Pensamiento Crítico Vol. 19 № 2, pp. 177-219

\title{
La economía ilegal del oro en el Perú: Impacto socioeconómico
}

\author{
Illegal gold economy in peru: socioeconomic effects
}

Víctor Torres $C .^{1}$

\section{RESUMEN}

El artículo analiza los principales desarrollos operados en el mercado aurífero nacional en lo que va del presente siglo. En particular, se detiene en los procesos de desconcentración en la producción y exportación de este metal ocurridos en medio del boom minero que vivió el país desde fines de 2002 hasta muy recientemente. Asimismo, analiza la expansión de la minería aurífera ilegal e informal, en medio del alza sostenida de la cotización internacional del oro que sustentó el boom minero y del debilitamiento productivo de la gran minería. En este marco, se cuantifica y valora la producción aurífera ilegal e informal, así como sus efectos en la recaudación fiscal.

Palabras claves: Oro, concentración de mercado, minería ilegal e informal, evasión tributaria.

\section{ABSTRACT}

The paper analyzes the main developments operated in the domestic gold market so far this century. In particular, it stops at the deconcentration in the production

1 Doctor en Economía por la Universidad La Sorbona (París I - Francia). Profesor Asociado de la Facultad de Ciencias Económicas de la UNMSM. E-mail: vtorresc1@unmsm.edu.pe. 


\section{Pensamiento Crítico Vol. 19. No 2}

and export of this metal occurred amid the mining boom experienced by the country since late 2002 until very recently. It also discusses the expansion of illegal and informal gold mining, amid the sustained rise in the international price of gold that supported the mining boom and productive weakening of large mining. In this framework, quantified and valued the illegal and informal gold production and its impact on tax revenues.

Keywords: Gold, market concentration, illegal and informal mining, tax evasion.

\section{Introducción}

Desde 2007, cuando publiqué un libro sobre la minería aurífera en el Perú (Torres 2007), esta actividad ha experimentado cambios sustanciales. En ese entonces, la producción aurífera que no provenía de empresas formalmente establecidas estaba focalizada en cinco regiones: Puno, Ica, Arequipa, La Libertad y -principalmenteMadre de Dios. Hoy, se desarrolla prácticamente a lo largo y ancho del país; y ya no se circunscribe a la extracción de oro, sino que se ha extendido a la extracción de plata, cobre y zinc.

El único concepto que se utilizaba para definir a este segmento de la producción aurífera nacional era el de "minería informal". Hoy, el glosario minero se ha enriquecido con el concepto de "minería ilegal". No es que esta no existiese antes de 2007: ocurría simplemente que nuestros "valores ambientales" aún no prestaban la importancia debida a los efectos nocivos que la minería ilegal ocasiona en el ecosistema y en la vida y la salud de las personas que se ven involucradas en esta actividad (contaminación por el uso del mercurio, alcoholismo, trabajo infantil, prostitución, explotación sexual de menores, entre otros). Los costos también son financieros, en términos de los ingresos fiscales que el Estado deja de recaudar.

En 2007, el sector minero nacional se encontraba en su máxima efervescencia: altas cotizaciones en los principales metales, que tenían su correlato en valores exportados cada vez mayores, crecientes utilidades y altos niveles de recaudación. La fiesta se interrumpió a fines de 2008, cuando estalló la crisis financiera mundial. Desde 2010, la bonanza continuó durante dos años más, pero ya no con el mismo frenesí, ni con las elevadas ganancias extraordinarias que caracterizaron a la etapa precrisis. En

\section{8}




\section{Víctor Torres Cuzcano}

la minería aurífera, estos desarrollos afectaron los altos índices de concentración que históricamente han predominado en este mercado.

Estos temas se analizan a continuación, con el objetivo de tener un conocimiento más actual de lo que ha ocurrido en el mercado aurífero nacional en lo que va del presente siglo. Para tal efecto, organizaremos nuestra exposición en cuatro secciones. En la primera, pasamos revista a la evolución reciente de la producción y exportación de oro, insistiendo en la influencia determinante que ha tenido la cotización internacional de este metal. En la segunda, cuantificamos los niveles de "desconcentración" en el mercado aurífero nacional, y subrayamos la presencia de productores y exportadores "golondrinos". En la tercera, proponemos una cuantificación de la minería ilegal e informal, en términos de cantidad y valor producido y exportado. En la cuarta, sugerimos una metodología para estimar la evasión tributaria que se produce en la minería ilegal/ informal. Finalmente, exploramos algunas conclusiones.

\section{La producción y exportación aurífera}

\subsection{Auge y caída de la producción}

Hasta 1994, la mayor parte del oro del Perú se producía de manera informal en el estrato "aluvial y lavaderos", el cual aportaba el $51.2 \%$ de la producción total de ese entonces. Las empresas formales eran poco más de 30 y se clasificaban en el estrato de la gran y mediana minería, que aportaba el $45.9 \%$ de la producción; y en el de la pequeña minería, con una participación de $3.9 \%$. En ese entonces, la producción aurífera nacional era bastante modesta: poco menos de 48 toneladas.

En la gran minería, la estadounidense Minera Yanacocha entró en producción en agosto de 1993; Compañía Minera Sipán, en 1997; y la canadiense Minera Barrick Misquichilca, en 1998. En la mediana minería, Compañía Aurífera Santa Rosa comenzó a producir en 1996 y Compañía Minera Ares lo hizo desde 1998. La producción de estas empresas vino a sumarse a la aportada por empresas de la mediana minería, como Compañía de Minas Buenaventura, Compañía Minera Poderosa, Minera Aurífera Retamas, entre otras. Desde la segunda mitad de la década de los noventa del siglo pasado, las grandes empresas transformaron la minería aurífera del Perú en 


\section{Pensamiento Crítico Vol. 19. № 2}

una producción a gran escala. Ello explica por qué desde 1990 y hasta el presente, el quinquenio 1995-1999 ha sido el de mayor expansión en la producción de oro en el Perú (191.6\%).

Al comenzar el presente siglo, la producción aurífera se había polarizado: de un lado, la gran y mediana minería, que para entonces ya concentraba el $87.3 \%$ de la producción; de otro, los informales ("aluvial y lavaderos"), con una participación relativa que había descendido a $12.4 \%$ (gráfico 1). La pequeña minería había casi desaparecido $(0.2 \%$ del total), en tanto que la minería artesanal aún no existía, al menos en el plano legal. Para entonces, la producción aurífera se había casi triplicado con respecto a 1994: 132.6 toneladas.

\section{GRÁFICO 1}

Oro: Producción por estratos 1990-2014 (part. \%)

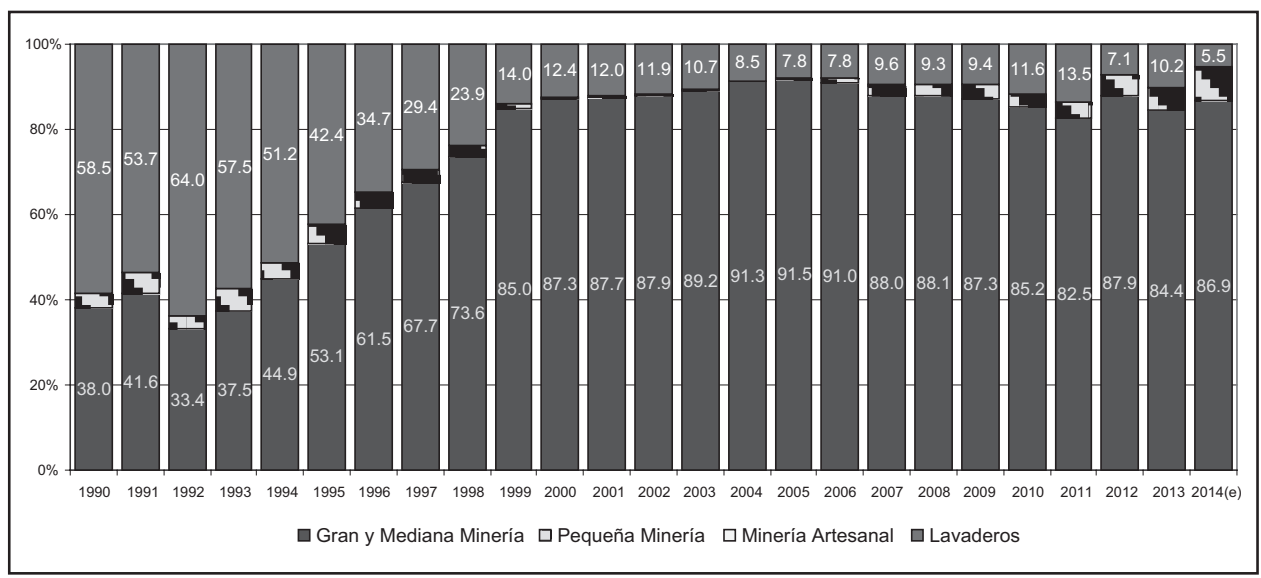

Fuente: Minem.

Elaboración propia.

Tras el boom minero de la última década, las referidas participaciones registraron pocas variaciones, que, sin embargo, no deben ser pasadas por alto. La minería informal (aluvial y lavaderos), que había bajado su participación relativa a 7.8\% hacia 2006, recuperó posiciones hasta ubicarse en 13.5\% durante 2011; desde entonces su producción bajó debido a las acciones implementadas por el actual gobierno para 


\section{Víctor Torres Cuzcano}

lograr su formalización. Según mis estimaciones, este estrato bajará su participación a 6\%, aproximadamente, durante 2014. Como veremos más adelante, esta menor participación relativa ha tenido su correlato en una expansión sin precedentes de aquella minería informal que no es registrada por el Ministerio de Energía y Minas (Minem).

De otro lado, se observa una progresiva mayor importancia de la pequeña minería, la que en algo vino a contrarrestar la menor producción de las empresas más grandes del sector a partir de 2006.

En efecto, la producción de la gran y mediana minería alcanzó un punto máximo en $2005^{2}$, para luego iniciar una tendencia descendente desde 2006, en plena cotización al alza del oro, a tal punto que entre 2005 y 2013 la producción nacional de oro cayó en $27.2 \%$ (gráfico 2). Durante el último quinquenio $2010-2014^{3}$, estimo que la producción de la gran y mediana minería se contraerá en $22.2 \%$ con respecto al quinquenio 20052009. Para estos mismos periodos, la producción informal registrada por el Minem se reducirá en $8.6 \%$, en tanto que la minería artesanal lo hará en $27.4 \%$.

En cambio, la pequeña minería incrementará su producción en $101.2 \%$. Dos razones, entre otras, explicarían este repunte de la pequeña minería. De un lado, el alza sostenida de la cotización del oro volvió rentable pequeñas minas que antes no habían sido explotadas debido a sus elevados costos de operación; de otro, este estrato estaría cobijando a aquellos productores que han decidido formalizar sus actividades, o a los que se han visto obligados a sincerar sus niveles de producción.

2 Durante 2005, la producción de oro se incrementó en 20.0\% debido, en particular, a la mayor producción de Yanacocha; pero, también por el inicio de operaciones del proyecto Alto Chicama de Minera Barrick Misquichilca en junio de ese año. Cf. BCRP: Memoria 2005.

3 Para 2014, la producción de oro es estimada. 


\section{Pensamiento Crítico Vol. 19. № 2}

\section{GRÁFICO 2}

Oro: Producción por estratos 1990-2013 (kg de contenido fino)

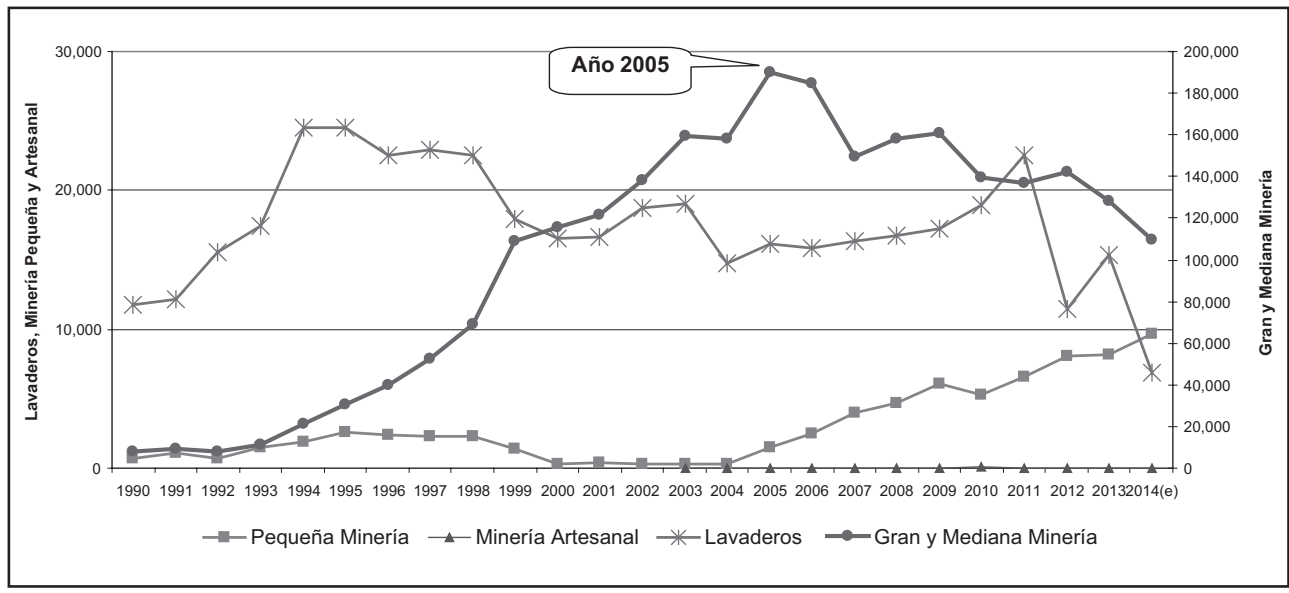

Fuente: Minem.

Elaboración Propia.

\subsection{Producción y precios}

¿Qué factores determinaron la menor producción de oro a partir de 2006 (-2.5\% ese año)? Dos principalmente: 1) desde 2006 hasta 2010, la principal explicación se encuentra en las restricciones derivadas del proceso productivo de las principales empresas del sector; 2) la tendencia a la baja en la cotización internacional del oro a partir de 2011. Un tercer factor podría ser los conflictos socio-ambientales.

En cuanto al primer factor, Minera Yanacocha contrajo su producción en $21.2 \%$ durante 2006 porque comenzó a extraer mineral de baja ley debido al alto contenido de sulfuros en sus zonas de explotación. Este previsible agotamiento de las zonas ricas en óxidos, y la demora en buscar alternativas, influyó en la menor producción de la empresa durante los años subsiguientes. Por su parte, Minera Barrick Misquichilca inició desde 2007 una caída ininterrumpida en su producción debido al agotamiento de la mina Pierina, que había iniciado operaciones a fines de 1998. Sin embargo, durante este periodo las exportaciones de oro seguían al alza porque los mayores precios compensaban con creces la menor producción.

\section{2}




\section{Víctor Torres Cuzcano}

El panorama cambió desde septiembre de 2011, pues a la menor producción se sumó la tendencia a la baja en la cotización del oro, lo cual influyó en la decisión empresarial de reducir costos e inversiones, acentuando así los menores niveles de producción y exportación de este metal (gráfico 3). Detengámonos en esta reacción inherente a la minería metálica.

Las inversiones en esta actividad productiva están influenciadas de manera determinante por la cotización internacional de los metales. En el caso del oro, la singular bonanza minera que vivió el Perú desde fines de 2002, con sus externalidades positivas en el conjunto de la economía nacional, fue resultado de los altos precios que fue alcanzando dicho metal, pero también de la mayor producción de importantes proyectos auríferos que entraron en operación desde la segunda mitad de la década de los 90 del siglo pasado. La virtuosa combinación de ambos factores: expansión de la producción y altos precios, determinó un efecto en cadena altamente positivo para la economía nacional: alza de la cotización internacional $\rightarrow$ mayor inversión $\rightarrow$ mayor producción $\rightarrow$ se acentúan los eslabonamientos y externalidades positivas $\rightarrow$ aumento de exportaciones $\rightarrow$ incremento de utilidades $\rightarrow$ mayor recaudación del Impuesto a la Renta $\rightarrow$ aumento del canon minero regional.

\section{GRÁFICO 3}

Oro: Producción y cotización mensual, enero 2003 - agosto 2014 (Periodo base: Enero 2001 = 100)

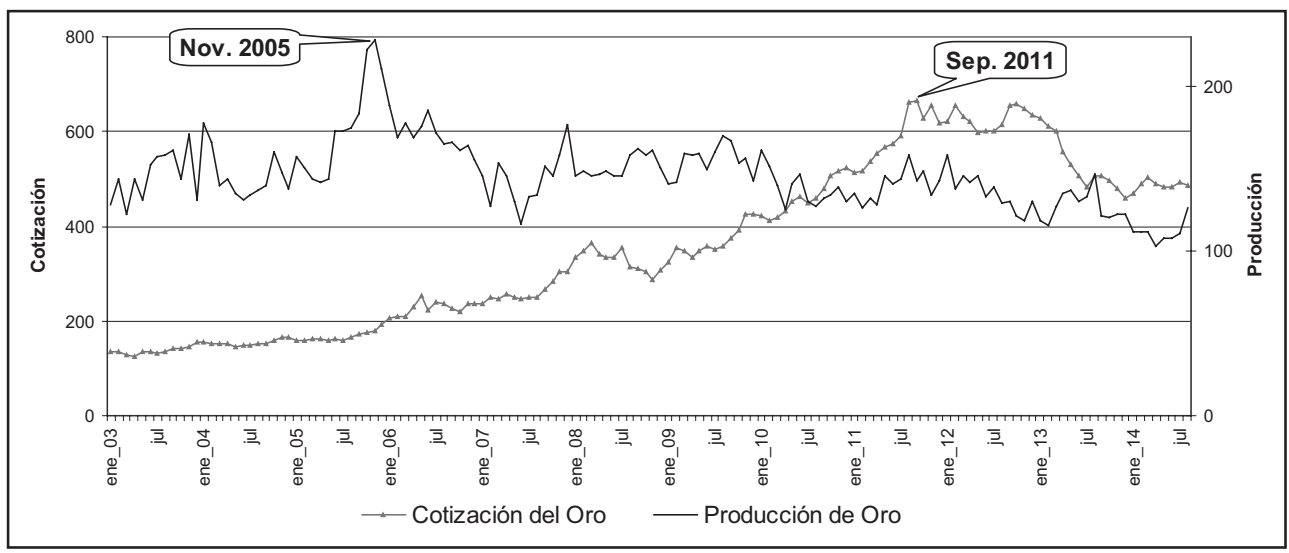

Fuente: Minem, BCRP.

Elaboración propia. 


\section{Pensamiento Crítico Vol. 19. No 2}

Este efecto en cadena se interrumpió cuando la cotización internacional de los metales comenzó a decaer. Frente a la crisis financiera de 2008 y sus efectos negativos en la demanda internacional de metales, por parte de China principalmente, la primera reacción de la gran minería fue reducir costos y postergar inversiones. Sin embargo, el oro -activo en el que las inversiones internacionales se refugian en periodos de incertidumbre- redujo su cotización internacional solo durante cinco meses: de julio a noviembre de 2008. Superado este bache, las inversiones en la minería aurífera nacional se recuperaron desde 2010, situación que se prolongó hasta cuando el precio del oro comenzó a bajar desde septiembre de 2011.

En respuesta a este nuevo escenario con precios a la baja, hacia 2013 la inversión anual conjunta de tres principales empresas de la minería aurífera -Minera Yanacocha, Minera Barrick Misquichilca y Cía. de Minas Buenaventura- se redujo en 56.0\% con respecto al año precedente ${ }^{4}$. Las consecuencias no se han dejado esperar: menor producción $\rightarrow$ contracción de las exportaciones $\rightarrow$ disminución de utilidades $\rightarrow$ menor recaudación $\rightarrow$ reducción del canon minero.

Según mis estimaciones, estas tres empresas habrían reducido su producción entre 2005 y 2014: Yanacocha en $-77.0 \%$, Barrick Misquichilca en $-50.0 \%$, Buenaventura en $-1.8 \%$. Asimismo, la minería informal que registra el Minem lo haría en $57.4 \%$ (gráfico 4).

Sin embargo, la cotización del oro sigue por encima de sus niveles de largo plazo; por tanto la menor inversión y producción debe entenderse como una sobre-reacción de la gran minería frente a un escenario en el que ya no está obteniendo las ganancias extraordinarias de los años precedentes ${ }^{5}$. No están perdiendo, están ganando menos.

4 Durante 2012, la inversión de estas tres empresas sumó US\$1,422 millones. Durante 2013 bajó a US\$ 625 millones. Cf. BCRP: Memoria 2013.

5 Para una cuantificación de las ganancias extraordinarias obtenidas por los principales grupos mineros nacionales durante el periodo de bonanza puede consultarse Torres (2013). 


\title{
Víctor Torres Cuzcano
}

\author{
GRÁFICO 4
}

Oro: Producción 1990-2014 (gramos de oro fino)

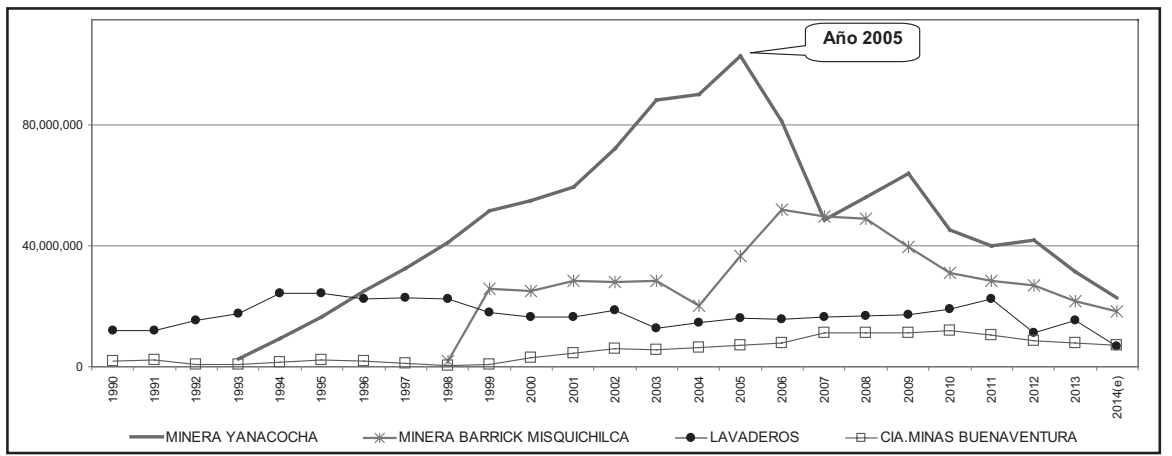

Fuente: Minem.

Elaboración propia.

Entre enero de 2002, año en que comienza la tendencia alcista del precio del oro, y septiembre de 2011, cuando alcanzó su pico más alto, la cotización de este metal pasó de US\$/oz.tr. 281.51 a US\$/oz.tr. 1,772.71; es decir, se multiplicó en poco más de seis veces. Desde esta última fecha hasta octubre de 2014, la cotización bajó a US\$/oz.tr. 1,222.49; es decir cayó en $31.0 \%$ (gráfico 5). Sin embargo, el promedio mensual de la cotización internacional del oro del periodo enero-octubre 2014 (US\$/oz.tr. 1,281.57) superaba en 3.5 veces la cotización mensual promedio de los 20 años que precedieron al 2002 (US\$/oz.tr. 363.00).

\section{GRÁFICO 5}

Oro: Cotización internacional mensual, enero 1985- octubre 2014

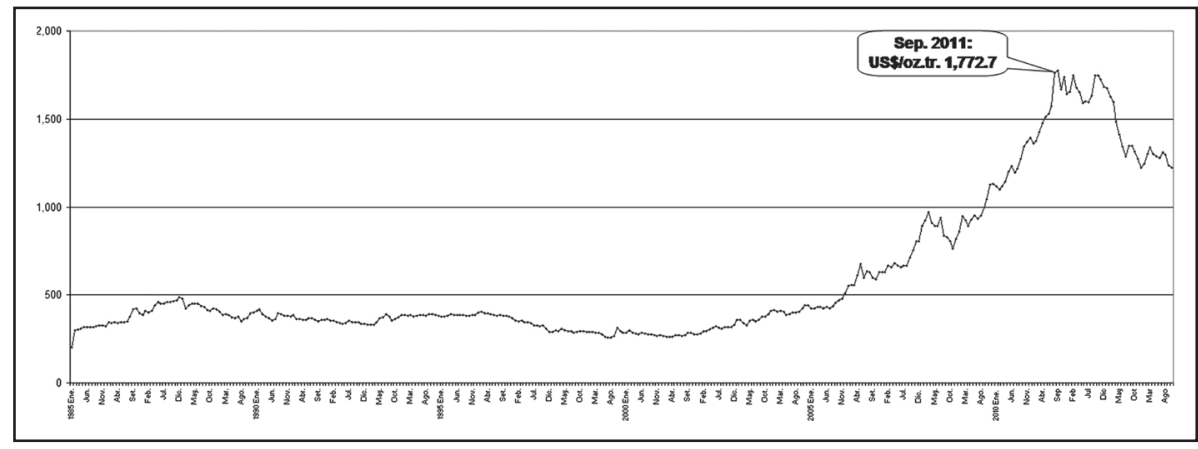

Fuente: BCRP.

Elaboración propia. 


\section{Pensamiento Crítico Vol. 19. No 2}

De otro lado, entre las razones que explican esta menor producción aurífera no puede obviarse el rol jugado por los conflictos socio-ambientales, que se acentuaron conforme se multiplicaban las ganancias mineras. Estos influyeron en la postergación de importantes proyectos auríferos en la gran y mediana minería (Torres, 2013). Lo sucedido con Minera Yanacocha S.R.L., la principal productora de oro en el Perú, grafica bastante bien esta situación. Esta empresa fue la principal responsable de la caída de la producción de oro a partir de 2006 debido a la menor ley del mineral que extrajo, pero también porque en agosto de ese año tuvo que paralizar parcialmente sus actividades productivas por protestas de la población de la ciudad de Cajamarca, las que finalmente la obligaron a cancelar su proyecto aurífero en Cerro Quilish (Cajamarca). Más adelante, tuvo que suspender de manera indefinida la explotación del proyecto aurífero Conga, también en Cajamarca.

Aunque en menor medida, otro factor que contribuye a explicar la menor producción aurífera en los años recientes se relaciona con las acciones que el actual gobierno ha venido llevando a cabo en Madre de Dios para erradicar la minería ilegal y "legalizar" a los mineros informales. Ello determinó que durante 2012 la producción aurífera informal de Madre de Dios, aquella que estima y registra el Minem, se redujera en cerca de la mitad con respecto a 2011.

\section{El proceso de desconcentración en el mercado del oro}

Si medimos los niveles de concentración en el mercado aurífero nacional mediante el Índice de Herfindahl-Hirschman ( $\mathrm{IHH})$, y retenemos la escala para interpretar este índice empleada por el Departamento de Justicia de los Estados Unidos, los resultados no dejan de sorprendernos.

\subsection{Concentración de la producción}

La producción de oro registró altos niveles de concentración de manera permanente entre 1990 y 2009 (más de 1,800 puntos), aunque con una tendencia descendente. La alta concentración en los primeros años de dicho periodo se debió a la participación preponderante de la minería informal (o aluvial). A partir de 1995, se explica por la entrada en plena producción de Minera Yanacocha. El ligero descenso del IHH entre 


\section{Víctor Torres Cuzcano}

1997 y 1999 se debe al inicio de la producción de Compañía Minera Sipán en 1997, y Minera Barrick Misquichilca en 1998, lo que redujo la importancia relativa de Minera Yanacocha.

Desde 2010, el índice de concentración bajó a "moderado" (menos de 1,800 puntos), acentuándose así una tendencia a la baja que se ha prolongado hasta el presente: durante 2013 y 2014 (enero-agosto) el IHH cayó a 895 y 769, respectivamente (gráfico 6). En consecuencia, actualmente la producción aurífera nacional registra un nivel bajo de concentración (menos de 1,000 puntos).

\section{GRÁFICO 6}

Oro: Concentración de la producción (según el índice de Herfindahl-Hirschman)

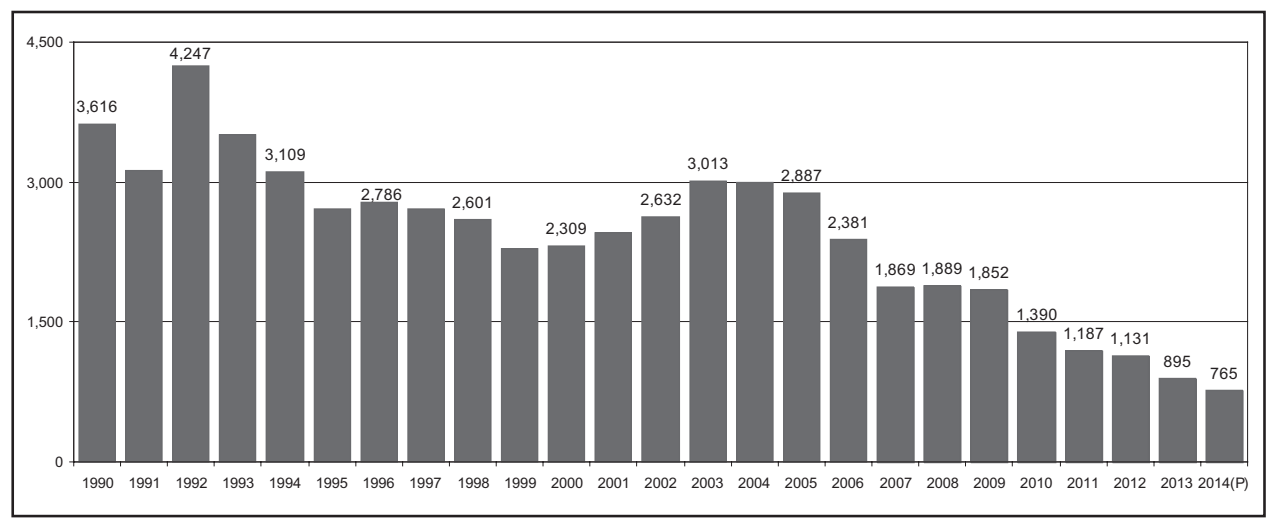

Fuente: Minem.

Elaboración propia.

¿Qué factores explican esta "desconcentración" de la producción aurífera en el Perú? Dos principalmente. De un lado, una cuasi atomización de los productores de oro, los cuales aumentaron de 41 en 2002, año en que se inicia el boom del precio de los metales, a 304 en 2012, para luego descender a 269 durante $2013^{6}$ (gráfico 7).

6 Estas cifras se refieren a los productores formales cuya producción es registrada por el Minem, pero incluye también la producción de los mineros informales a los que el Minem agrupa como si se tratasen de un solo productor o titular. En consecuencia, el IHH que hemos calculado considera a la producción aurífera informal como si proviniese de un solo productor. 


\section{GRÁFICO 7}

Oro: Producción, $\mathrm{N}^{\circ}$ de productores y concentración IHH (año base $1990=100$ )

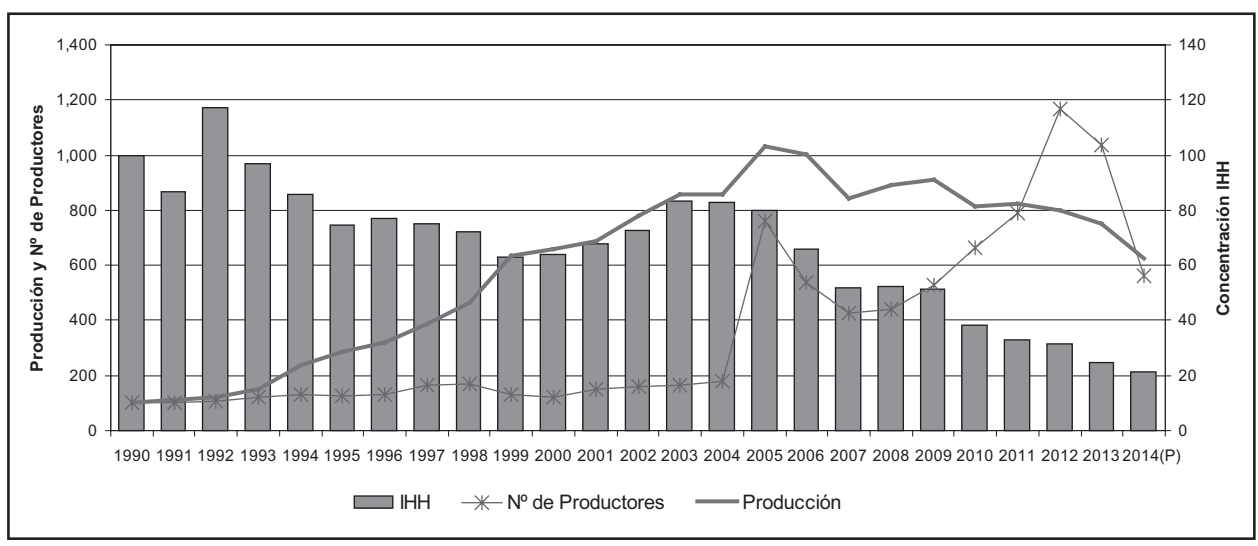

Fuente: Minem.

Elaboración propia.

De otro lado, el factor determinante tiene que ver con la ya comentada contracción de la producción de las empresas más importantes del sector. Así, la caída de la producción aurífera en 27.2\% entre 2005 y 2013, tuvo como principales responsables a Minera Yanacocha, cuya producción se contrajo en $69.3 \%$, y Minera Barrick Misquichilca, que bajó su producción en $40.5 \%$. Para estos mismos años, la producción informal cayó en $4.3 \%$.

En consecuencia, los niveles de concentración se vinieron abajo porque la gran minería aurífera redujo drásticamente su producción. Entre 1990 y 2014 (enero-agosto) los cuatro principales productores bajaron su participación relativa en la producción total de oro de $80.2 \%$ a $43.4 \%$ (cuadro 1). Es decir, mientras la torta se reducía considerablemente, iba en aumento el número de comensales, disminuyendo así los niveles de concentración. 


\section{Víctor Torres Cuzcano}

CUADRO 1

Producción de oro: Concentración de los cuatro primeros productores

\begin{tabular}{|c|c|c|c|c|c|c|c|c|c|}
\hline \multicolumn{2}{|l|}{1990} & \multicolumn{2}{|l|}{2000} & \multicolumn{2}{|l|}{2005} & \multicolumn{2}{|l|}{2010} & \multicolumn{2}{|c|}{2014 (enero-agosto) } \\
\hline Productor & Part.\% & Productor & Part.\% & Productor & Part.\% & Productor & Part.\% & Productor & Part.\% \\
\hline Aluvial y Lavaderos & 58.5 & Minera Yanacocha & 41.5 & Minera Yanacocha & 49.6 & Minera Yanacocha & 27.7 & Minera Yanacocha & 19.4 \\
\hline Cía. Minas Buenaventura & 8.6 & Min. Barrick Misquichilca & 19.0 & Min. Barrick Misquichilca & 17.6 & Min. Barrick Misquichilca & 18.9 & Min. Barrick Misquichilca & 12.9 \\
\hline Cía Minera Poderosa & 8.5 & Aluvial y Lavaderos & 12.4 & Aluvial y Lavaderos & 7.7 & Aluvial yLavaderos & 11.6 & Cons. Minero Horizonte & 5.6 \\
\hline Min. Aurifera Retamas & 4.6 & Min. Aurifera Retamas & 4.0 & Cía. Minera Ares & 3.5 & Cía. Minas Buenaventura & 7.3 & Aluvial y Lavaderos & 5.5 \\
\hline TOTAL & 80.2 & TOTAL & 76.9 & TOTAL & 78.4 & TOTAL & 65.5 & TOTAL & 43.4 \\
\hline
\end{tabular}

Fuente: Minem.

Elaboración propia.

Pero ¿cómo explicar un escenario en el cual se reducen los niveles de producción pero al mismo tiempo aumenta el número de productores? Ello se debe a la presencia de productores "golondrinos". Durante 2012, año en el cual se registra un incremento inusual de productores o titulares, de los 304 cuya producción fue registrada por el Minem, poco más de la tercera parte (104 titulares) declaraba su producción por primera vez.

Desde 2005, cuando comienza a aumentar la cantidad de productores, hasta 2013, el Minem registra la producción de un total de 496 titulares (cuadro 2). De este total, solo el $15.3 \%$ produjo regularmente; es decir, registraron producción durante 7 o más años de dicho periodo. En el otro extremo, la mayor parte de productores ( $54.0 \%$ del total) registraron producción solo uno o dos años. Por lo general, esta producción corresponde a muy pocos meses en uno o dos años. ¿Y qué hacen estos productores el resto del año? Es probable que, en respuesta a las medidas de presión para formalizar a los productores de Madre de Dios adoptadas por el actual gobierno, estos hayan optado por "legitimar" parte de su producción, pero la mayor parte de esta la seguirían obteniendo de manera informal o ilegal.

CUADRO 2

Productores de oro: Frecuencia de producción durante 2005-2013

\begin{tabular}{|ccr|}
\hline Frecuencia en años & $\mathrm{N}^{\circ}$ Productores & Part.\% \\
\hline $7-9$ & 76 & 15.3 \\
$3-6$ & 152 & 30.6 \\
$1-2$ & 268 & 54.0 \\
& 496 & 100.0 \\
\hline
\end{tabular}

Fuente: Minem.

Elaboración propia. 


\section{Pensamiento Crítico Vol. 19. № 2}

De los 268 productores "golondrinos", solo el 40.7\% (109 productores) figuraba en la relación de productores de oro del Minem ${ }^{7}$. De estos 109 productores, ocho estaban en la categoría de gran y mediana minería; 45, en la pequeña minería; y 56 en la minería artesanal.

\subsection{Concentración de las exportaciones}

En el mercado de exportación del oro, los índices de concentración han seguido más o menos la misma tendencia observada en la producción. Una alta concentración desde 1995 que se sostuvo hasta 2006 (más de 1,800 puntos), debido a la participación de Minera Yanacocha; para bajar a niveles "moderados" desde 2007 (menos de 1,800 puntos), y alcanzar bajos niveles de concentración desde 2011 (menos de 1,000 puntos) (gráfico 8).

\section{GRÁFICO 8}

Oro: Concetración de las exportaciones (según el índice de Herfindahal-Hischman)

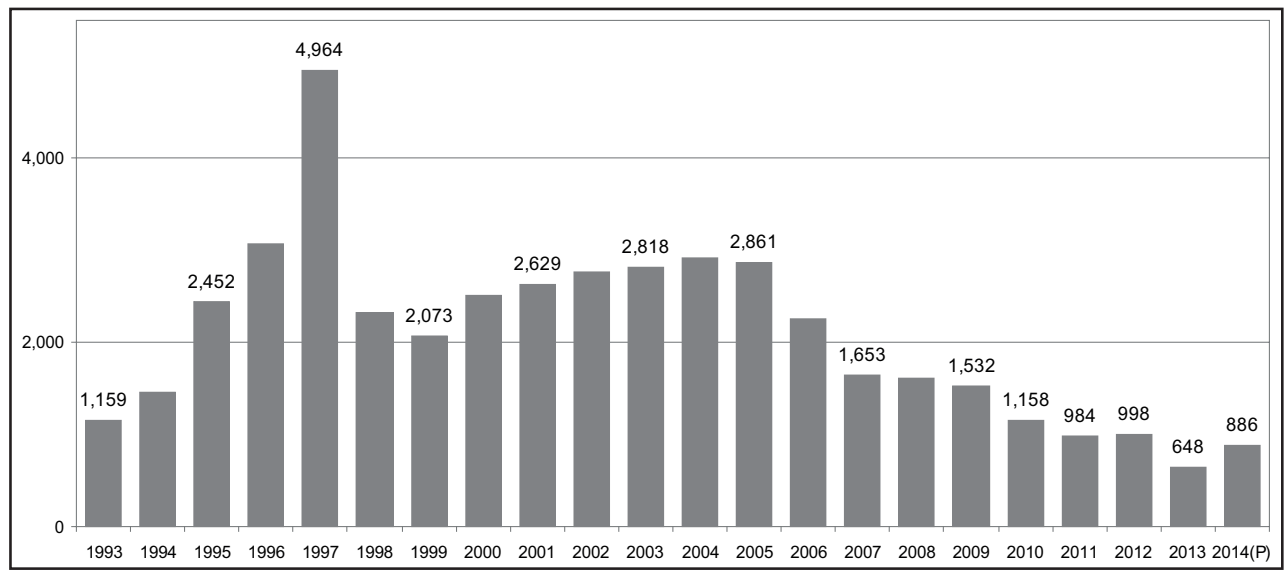

Fuente: ADUANET.

Elaboración propia.

También en este caso la "desconcentración" observada desde 2007 resultó del efecto combinado entre menor importancia relativa de los principales exportadores $e$ incremento del número de exportadores.

7 Declaración estadística Estamin año 2013. Ver Anexos en Minem: Anuario Minero 2013 (www.Minem. gob.pe). 


\section{Víctor Torres Cuzcano}

En el primer caso, el principal exportador -Minera Yanacocha- redujo sus exportaciones en $32.1 \%$ durante 2007 con respecto al año precedente, debido a sus menores niveles de producción. Entre 2000 y 2006, la empresa había concentrado en promedio anual el $47.0 \%$ del valor exportado, participación que bajó a $24.4 \%$ durante 2007-2013. Entre 2005 y 2013 los cuatro principales exportadores redujeron su participación relativa dentro del total exportado de $79.0 \%$ a $42.1 \%$ (cuadro 3 ).

CUADRO 3

Exportación de oro: Concentración de los cuatro primeros exportadores

\begin{tabular}{|c|c|c|c|c|c|c|c|c|c|}
\hline \multicolumn{2}{|l|}{1993} & \multicolumn{2}{|l|}{2000} & \multicolumn{2}{|l|}{2005} & \multicolumn{2}{|l|}{2010} & \multicolumn{2}{|l|}{2013} \\
\hline Exportador & Part.\% & Exportador & Part.\% & Exportador & Part.\% & Exportador & Part.\% & Productor & Part.\% \\
\hline Proces. Sudamericana & 21.6 & Minera Yanacocha & 44.5 & Minera Yanacocha & 49.2 & Minera Yanacocha & 23.4 & Minera Yanacocha & 17.8 \\
\hline Minera Aurifera Retamas & 14.9 & Min. Barrick Misquichilca & 20.8 & Min. Barrick Misquichilca & 18.2 & Min. Barrick Misquichilca & 15.9 & Min. Barrick Misquichilca & 12.0 \\
\hline Minera Yanacocha & 11.2 & Cía. Minera Ares S.A. & 4.9 & Proces. Sudamericana & 7.7 & Proces. Sudamericana & 12.8 & Cía. Minas Buenaventura & 7.8 \\
\hline Banco Wiese Sudameris & 9.6 & Universal Metal Trading & 4.1 & Cía. Minas Buenaventura & 3.9 & Universal Metal Trading & 9.2 & Darsahn International Inc. & 4.5 \\
\hline TOTAL & 57.3 & TOTAL & 74.3 & TOTAL & 79.0 & TOTAL & 61.2 & TOTAL & 42.1 \\
\hline
\end{tabular}

Fuente: www.Minem.gob.pe Elaboración propia.

A ello se sumó la "explosión" del número de exportadores desde 2008. Entre 2007 y 2013, estos casi se cuadriplicaron: de 35 a 130 exportadores (gráfico 9).

GRÁFICO 9

Oro: Exportaciones, $\mathrm{N}^{\circ}$ de exportaciones y concentración IHH (año base: $1993=100$ )

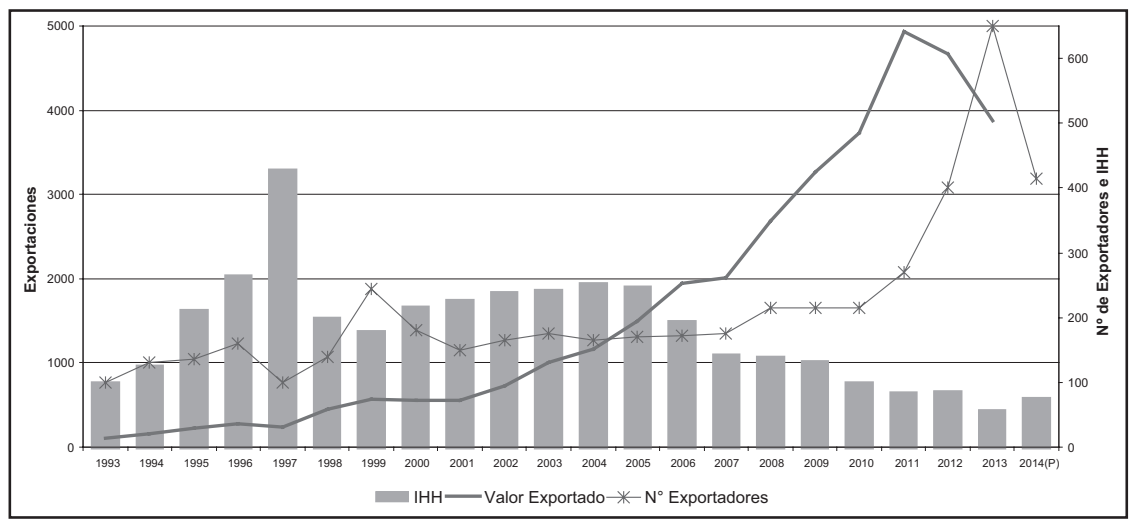

Fuente: ADUANET.

Elaboración propia. 


\section{Pensamiento Crítico Vol. 19. No 2}

En este caso, también estamos frente a exportadores "golondrinos", que realizan esta actividad muy pocas veces y luego no se vuelve a saber más de ellos. De los 130 que exportaron durante 2013, 69 lo hacían por primera vez; es decir, poco más de la mitad de los exportadores de ese año (53.1\%) nunca antes había exportado oro. Asimismo, durante los siete años del periodo 2007-2013, de un total de 167 exportadores, solo el 20.4\% (34 exportadores) exportó de manera frecuente (cinco o más años); en el otro extremo, el 68.3\% (114 exportadores) exportó solo durante 1 o 2 años (cuadro 4). Se trata, por lo general, de exportadores que efectuaron esta actividad durante muy pocos meses de cada año.

CUADRO 4

Exportadores de oro: Frecuencia de exportación durante 2007-2013

\begin{tabular}{ccr}
\hline Frecuencia en años & $\mathrm{N}^{\circ}$ Exportadores & Part.\% \\
\hline $5-7$ & 34 & 20.4 \\
$3-4$ & 19 & 11.4 \\
$1-2$ & 114 & 68.3 \\
& 167 & 100.0 \\
\hline
\end{tabular}

Fuente: www.aduanet.gob.pe Elaboración propia.

De los 114 exportadores "golondrinos", solo siete figuran en el directorio de productores de oro del Minem: Cía. Minera Minaspampa S.A.C., Minsur S.A., Apumayo S.A.C., Sociedad Minera el Brocal S.A., Comunidad Aurífera Relave S.A., Cía. Minera Chuvilca S.A. y Corporación Minera Libra S.A.C. Las cuatro primeras son empresas de la gran y mediana minería; las tres últimas, de la pequeña minería. Otros 23 figuran en el Directorio Minero del Minem?: siete en la categoría de gran y mediana minería, 10 en minería artesanal, y seis en pequeña minería. Los 84 exportadores restantes no figuraban en ninguno de dichos directorios.

Este elevado incremento en el número de productores y exportadores se podría explicar porque el alza de la cotización internacional del oro volvió muy rentable la producción y exportación de este metal. Sin embargo, el que se trate de operaciones muy eventuales, y efectuadas por empresas pequeñas o artesanales en la mayor parte de los casos, hace muy probable que estas se muevan entre la formalidad y la ilegalidad.

8 Ibíd.

9 Directorio Minero al 14.11.14. 


\section{Víctor Torres Cuzcano}

En los últimos tres años, se ha hecho público varios casos de exportaciones de oro de procedencia ilegal en los que -precisamente- se han visto involucrados varios exportadores "golondrinos". Mencionemos algunos ejemplos:

- Axbridge Gold Corp S.A.C., Oxford Gold Corporation S.A.C. y Darsahn International Inc. figuran entre las 114 empresas arriba mencionadas ${ }^{10}$. Esta última fue la cuarta exportadora más importante de oro durante 2013, el único año en el que exportó y lo hizo solo durante cuatro meses. Las otras dos también exportaron entre cuatro y seis meses durante 2012 y 2013. Estas tres empresas, vinculadas a la compañía Axbridge Corp. registrada en las Islas Vírgenes Británicas, vienen siendo investigadas -junto con otras 60 exportadoras de oro- "por sus nexos con la minería ilegal en Madre de Dios, Cusco y Puno, comprar toneladas de metal de origen ilícito, usar testaferros en empresas fantasmas, registrar operaciones financieras sospechosas y por tener investigaciones por lavado a raíz de la incautación de lingotes $y$ dinero en efectivo" ${ }^{11}$.

- Titán Contratistas Generales SAC exportó durante tres meses de 2013. Esta empresa es propiedad de Rocío Torres Carcasi, quien consigue el oro en La Rinconada en Puno. Luego de largos años de extraer oro de manera informal, la empresa se formalizó en enero de 2008 y figura en el directorio minero como pequeña minería. Rocío Torres es también gerente de Cía. Minera Titán SAC empresa que formalmente existe desde junio de 2003 y se clasifica en la actividad "explotación de otras minas y canteras". Esta empresa, sin embargo, nunca produjo según los registros de producción de oro del Minem, y tampoco figura en la relación de empresas productoras de este metal. En agosto de 2013, se hizo público que Rocío Torres había comprado una finca taurina en España valorizada en US\$ 8 millones ${ }^{12}$.

- Comercializadora de Minerales Rivero SAC, que embarcó oro durante cuatro meses de 2013, no figura en el registro de productores de oro ni en el directorio minero del Minem. Hacia fines de 2013, la Sunat ${ }^{13}$ le incautó media tonelada de oro debido a la sospecha de su procedencia ilícita; este cargamento, sin embargo, fue recuperado

10 No hemos logrado ubicar a ninguna de estas tres empresas en el directorio de productores de oro ni en el directorio minero.

11 Cf. http://elcomercio.pe/peru/madre-de-dios/mitad-exportadoras-oro-mira-mineria-ilegal-noticia-1708977.

12 Cf. http://www.larepublica.pe/11-08-2013/la-reina-de-la-rinconada-compra-la-finca-de-rocio-jurado-y-jose-ortega-cano.

13 Superintendencia Nacional de Aduanas y de Administración Tributaria. 


\section{Pensamiento Crítico Vol. 19. $N^{\circ} 2$}

por la referida empresa días después, en una operación que contó con el apoyo de algunos fiscales (de Ucayali, del Callao) y de operadores del Sr. Rodolfo Orellana, como el coronel PNP (r) Benedicto Jiménez, ambos actualmente en prisión.

Se ha informado también que durante 2012, un grupo de exportadores ubicados en Puerto Maldonado, Mazuko y Huepetuhe, en donde están los mayores productores de oro ilegal, enviaron a refinerías de Suiza 25 toneladas de oro ${ }^{14}$.

\section{De la minería informal a la minería ilegal}

Uno de los primeros documentos oficiales en el que se menciona el concepto de minería ilegal es el Decreto de Urgencia $\mathrm{N}^{\circ}$ 012-2010, publicado el 18 de febrero de 2010, el cual declara de interés nacional el ordenamiento minero en el departamento de Madre de Dios. En dicha norma, sin embargo, el concepto es utilizado conjuntamente con el de "minería aurífera informal", sin establecerse una explícita diferencia entre ambos, incluso si el Artículo $2^{\circ}$ de dicha norma establece zonas de exclusión minera en el referido departamento. Desde entonces, las sucesivas normas que han buscado regular/erradicar esta actividad han ido afinando el concepto de "minería aurífera ilegal", vinculándolo cada vez más con sus efectos nocivos en el ecosistema y en la vida de las personas.

El 28 de febrero de 2012, el Decreto Legislativo $N^{\circ} 1102$, que incorpora al Código Penal los delitos de minería ilegal, al incluir el Artículo $307^{\circ}$-A, establece que el delito de minería ilegal se comete en cualquiera de los siguientes supuestos:

1. En zonas no permitidas para el desarrollo de actividad minera.

2. En áreas naturales protegidas, o en tierras de comunidades nativas, campesinas o indígenas.

3. Utilizando dragas, artefactos $\mathrm{u}$ otros instrumentos similares.

$14 \mathrm{Cf} . \quad \mathrm{http}: / /$ elcomercio.pe/lima/sucesos/aduanas-incauto-media-tonelada-oro-ilegal-us18-millones-noticia1683890 ?ref $=$ nota_peru\&ft=mod_leatambien\&e $=$ titulo. 


\section{Víctor Torres Cuzcano}

4. Si el agente emplea instrumentos u objetos capaces de poner en peligro la vida, la salud o el patrimonio de las personas.

5. Si se afecta sistemas de irrigación o aguas destinados al consumo humano.

6. Si el agente se aprovecha de su condición de funcionario o servidor público.

7. Si el agente emplea para la comisión del delito a menores de edad u otra persona inimputable.

Recién en el Decreto Legislativo $\mathrm{N}^{\circ} 1105$, publicado el 19 de abril de 2012, que establece disposiciones para el proceso de formalización de las actividades de pequeña minería y minería artesanal, se define de manera explícita lo que es la "minería ilegal" y se la diferencia de la "minería informal". En resumen, según el Artículo $2^{\circ}$ de dicha norma, "toda actividad minera ejercida en zonas en las que esté prohibido el ejercicio de actividad minera, se considera ilegal". En tanto que la minería informal es aquella actividad minera que es realizada sin cumplir con las exigencias de las normas de carácter administrativo, técnico, social y medioambiental que la regulan, en zonas no prohibidas para la actividad minera.

Así, para efectos prácticos, si se extrae -o no- oro en zonas de exclusión minera ha quedado como el criterio principal para diferenciar entre minería aurífera ilegal $e$ informal, respectivamente.

Si bien la minería ilegal e informal se practica actualmente en 21 de las 25 regiones del país, la que se lleva a cabo en la región de Madre de Dios destaca de manera particular, no solo por concentrar la mayor parte de esta actividad productiva (medida en términos de cantidad de trabajadores involucrados y participación relativa en la producción nacional de oro), sino también por sus efectos nefastos en el ecosistema: 50 mil hectáreas de bosques arrasados en dicho territorio, las cuales equivalen a la quinta parte de Lima Metropolitana ${ }^{15}$; gran parte de los ríos de la región han sido contaminados con mercurio y cianuro.

15 Cf.http://www.minam.gob.pe/mineriailegal/2014/01/31/especial-de-mineria-ilegal-como-nace-el-oroilicito/. Para una comprensión y análisis más detallados de los efectos en el ecosistema ocasionados por la minería ilegal/informal puede consultarse la amplia información que publica el Ministerio del Ambiente (MINAM) en su página web (www.minam.gob.pe), así como las publicaciones de la ONG CooperAcción (www.cooperaccion.org.pe). 


\section{Pensamiento Crítico Vol. 19. No 2}

\subsection{La estimación y registro oficial de la producción informal}

En el Perú, la cantidad de oro efectivamente producida por la minería ilegal o informal, así como el número de productores involucrados en estas actividades aún se mantienen en el campo de las estimaciones gruesas. En cuanto al número de productores, las cifras fluctúan en torno a 100,000 personas; pero también están las que llegan a quintuplicar dicha cifra ${ }^{16}$. En lo referente a la producción, actualmente el Minem estima y registra solo la producción informal de la región de Madre de Dios.

Hasta el año 2000, las estadísticas del Minem estimaban y registraban la producción informal de oro en el país bajo la denominación "Producción Aluvial y Lavaderos", diferenciándola así de la producción de las pocas empresas formales que en ese entonces operaban en la minería aurífera nacional. Esta "Producción Aluvial y Lavaderos" era una estimación gruesa que el Minem hacía de la producción informal de cuatro regiones: Madre de Dios, Puno, Sur Medio (Ica, Nazca, Arequipa) y Costa norte (La Libertad-Pataz).

Durante 2001 y 2002, el Minem comienza a registrar la producción informal de dichas regiones bajo la denominación de "Productores Artesanales", estrato legalmente vigente en el país desde enero de $2002^{17}$, considerando a cada una de las cuatro regiones arriba mencionadas como "Empresa" o "Titular". Desde 2003 hasta el presente, el Minem estima y registra solo la producción informal del "Titular" Madre de Dios. Ese año y durante 2004, esta producción se registró dentro del estrato "Productores Artesanales", el cual coexistía con el de "Minería Artesanal", para la confusión de no pocos de los que regularmente consultamos las estadísticas de dicho Ministerio. Desde 2005, la producción informal del "Titular" Madre de Dios pasó a ser clasificada como "Gran y Mediana Minería".

16 La Sociedad Nacional de Minería en Pequeña Escala -Sonamipe- estima en más de 500 mil el número de mineros informales. Cf. http://gestion.pe/mercados/mineria-informal-reto-saneamiento-2090060

17 El 24 de enero de 2002, se promulgó la Ley No 27651, Ley de Formalización y Promoción de la Pequeña Minería y Minería Artesanal, la cual introdujo el estrato de "minería artesanal" o "productor minero artesanal". La minería artesanal es definida como aquella actividad que se sustenta en la utilización intensiva de mano de obra. Además, tiene la característica de utilizar equipos básicos como lampas, picos, combas, barretas, cinceles, carretillas, carros mineros, zarandas, quimbaletes, maritatas, tolvas, perforadoras eléctricas y bombas eléctricas de hasta cuatro pulgadas de diámetro y de hasta $25 \mathrm{HP}$ y demás elementos y equipos similares, para la extracción y beneficio de sustancias auríferas, cupríferas, polimetálicas y no metálicas (Torres 2007). 


\section{Víctor Torres Cuzcano}

Para complicar más las cosas, desde 2009 hasta el presente, la información mensual de producción aurífera por empresa o titular, publicada por el Minem en su página web ${ }^{18}$, eliminó la clasificación "Gran y Mediana Minería" y la reemplazó por la de "Régimen General", la cual -dicho sea de paso- no está contemplada en la Ley General de Minería. En consecuencia, actualmente el Minem clasifica la producción informal de Madre de Dios dentro del "Régimen General".

Así, desde 2003 se dejó de estimar y registrar la producción informal de Puno, sur medio y costa norte; tampoco se estima/registra -claro está- la producción informal que se produce en otras regiones del país. Debe precisarse que hasta 2002 la producción informal de Madre de Dios era la única que el Minem registraba como producción aurífera en dicha región; desde 2003, también registra la producción individual de otras empresas o titulares clasificados en otros estratos.

Actualmente, la región de Madre de Dios destaca no solo por concentrar la mayor parte de la producción y productores informales de oro del Perú, sino también porque concentra la mayor parte de los productores formales; sin embargo, este resultado está muy influenciado por la presencia de los "productores golondrinos".

Según las cifras que publica el Minem, entre 2007 y 2013, esta región concentró entre $55.0 \%$ y $74.0 \%$ de los productores formales de oro del país; niveles de concentración que son aún mayores en el caso de la minería artesanal (entre $88.0 \%$ y 100.0\%) (cuadro 5). En la pequeña minería, los niveles de concentración fueron bastante elevados hasta 2012 (72.3\% del total ese año), pero bajó a 27.3\% durante 2013. En cuanto al "régimen general" (gran y mediana minería) la región de Madre de Dios explicó el 66.5\% del total de productores durante 2013. Durante estos años, su participación relativa en la producción aurífera nacional ha fluctuado entre $7.6 \%$ y $13.6 \%$, ubicándose en $10.6 \%$ durante 2013.

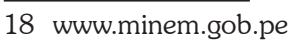




\title{
Pensamiento Crítico Vol. 19. № 2
}

\author{
CUADRO 5
}

Producción de oro: Participación (\%) de la región Madre de Dios

\begin{tabular}{|c|c|c|c|c|c|c|}
\hline \multirow{2}{*}{ CLASIFICACIÓN } & \multicolumn{2}{|c|}{ MADRE DE DIOS (A) } & \multicolumn{2}{|c|}{ TODAS LAS REGIONES (B) } & \multicolumn{2}{|c|}{ (A) $/(B) * 100$} \\
\hline & $\mathrm{N}^{\circ}$ Productores & Producción $^{2 /}$ & $\mathrm{N}^{\circ}$ Productores & Producción $^{2 l}$ & $\mathrm{~N}^{\circ}$ Productores & Producción $^{2 /}$ \\
\hline \multicolumn{7}{|l|}{ PEQUEÑA MINERÍA } \\
\hline 2007 & 35 & 82,024 & 47 & $4,018,492$ & 74.5 & 2.0 \\
\hline 2011 & 96 & 123,922 & 117 & $6,542,549$ & 82.1 & 1.9 \\
\hline 2012 & 68 & 408,947 & 94 & $8,048,910$ & 72.3 & 5.1 \\
\hline 2013 & 12 & 49,495 & 44 & $8,173,018$ & 27.3 & 0.6 \\
\hline \multicolumn{7}{|l|}{ MINERÍA ARTESANAL } \\
\hline 2007 & 24 & 10,655 & 27 & 31,760 & 88.9 & 33.5 \\
\hline 2011 & 39 & 18,649 & 42 & 40,363 & 92.9 & 46.2 \\
\hline 2012 & 25 & 28,642 & 27 & 29,829 & 92.6 & 96.0 \\
\hline 2013 & 4 & 1,959 & 4 & 1,959 & 100.0 & 100.0 \\
\hline \multicolumn{7}{|l|}{ RÉGIMEN GENERALl' } \\
\hline 2007 & 3 & $16,373,295$ & 37 & $166,185,612$ & 8.1 & 9.9 \\
\hline 2011 & 3 & $22,491,851$ & 46 & $159,603,805$ & 6.5 & 14.1 \\
\hline 2012 & 132 & $11,834,049$ & 183 & $153,465,927$ & 72.1 & 7.7 \\
\hline 2013 & 163 & $16,024,370$ & 221 & $143,311,095$ & 73.8 & 11.2 \\
\hline \multicolumn{7}{|l|}{ TOTAL } \\
\hline 2007 & 62 & $16,465,974$ & 111 & $170,235,864$ & 55.9 & 9.7 \\
\hline 2011 & 138 & $22,634,422$ & 205 & $166,186,717$ & 67.3 & 13.6 \\
\hline 2012 & 225 & $12,271,637$ & 304 & $161,544,666$ & 74.0 & 7.6 \\
\hline 2013 & 179 & $16,075,824$ & 269 & $151,486,072$ & 66.5 & 10.6 \\
\hline
\end{tabular}

1/ En 2007, el Minem lo clasificaba como "Gran y Mediana Minería". Incluye el estimado de la producción informal de Madre de Dios.

2/ Gramos de oro fino.

Fuente: Minem.

Elaboración propia.

¿Qué factores han determinado que la minería aurífera ilegal o informal se convierta en una suerte de pandemia en el Perú? Tres principalmente: el alza sostenida del precio internacional del oro que justificó con creces el riesgo de operar en la ilegalidad/informalidad, las restricciones estructurales de nuestra economía para generar adecuados puestos de trabajo, y una preocupante debilidad institucional.

Este último aspecto ayuda a comprender por qué el largo camino recorrido desde que comenzó el presente siglo en aras de la formalización ha tenido tan poco éxito. No 


\section{Víctor Torres Cuzcano}

se trata de la debilidad institucional de un gobierno en particular, sino la del Estado mismo. Descontando la Ley de Formalización y Promoción de la Pequeña Minería y Minería Artesanal de enero de 2002, que en la práctica no tuvo mayor efecto, desde 2010 se ha venido construyendo un marco legal contra la minería ilegal y a favor de la formalización de las actividades mineras ejercidas en zonas no prohibidas. El 19 de abril de 2012, se dio inicio al más reciente esfuerzo por formalizar a los mineros informales.

En una primera etapa, estos tenían que presentar una "declaración de compromiso" dentro de un proceso que debía prolongarse durante dos años, hasta el 19 de abril de 2014. Durante este periodo, los mineros informales tenían la ventaja de continuar con su actividad productiva. Luego, se pasaría a la etapa de "saneamiento" del proceso de regularización de las actividades mineras, la cual se prolongaría hasta 2016. Hacia inicios de 2014, 70,858 mineros informales habían presentado la referida declaración, pero solo el $15 \%$ había avanzado con la presentación de documentos para su formalización. Solo $5 \%$ de los mineros con declaración de compromiso cuenta con Registro Único de Contribuyente $(\mathrm{RUC})^{19}$. Frente a esta decepcionante realidad, cumplido el plazo del 19 de abril de 2014, el gobierno lo tuvo que ampliar por un año más ${ }^{20}$.

En medio de esta debilidad institucional, la bonanza minera fue caldo de cultivo para la extensión de la minería ilegal e informal, la que ha cobijado y potenciado actividades ilícitas, como el "lavado" de dinero producto del narcotráfico, pero también se han amasado fortunas sin pagar impuestos.

\subsection{Producción ilegal: una estimación}

Al menos desde 1998, y hasta 2002, el volumen de oro exportado guardaba estrecha correspondencia con el volumen producido. Desde 2003, cuando la cotización del oro comienza a subir de manera acentuada y sostenida, el volumen exportado de oro se fue divorciando del volumen de producción que registra el Minem; en los primeros años de manera leve, para luego acentuarse desde 2007 hasta 2013 (gráfico 10). ¿De dónde provino el oro que se exportó, pero cuya producción no figura en los registros oficiales del Minem?

19 Cf. http://gestion.pe/mercados/mineria-informal-reto-saneamiento-2090060.

20 Desde marzo de 2014, la Sunat comenzó el proceso de registro único de usuarios de mercurio y cianuro. 
El elevado incremento de "productores golondrinos" en la minería aurífera formal es un buen indicador de lo sucedido en la producción ilegal e informal de este metal. La cantidad de productores y la producción de oro en el mercado ilegal e informal también debieron haber aumentado de manera considerable a partir de esos años, debido en buena medida a que se fue acentuando el uso de métodos de producción semimecanizados que emplean más trabajadores, con el consecuente aumento en el ritmo de sus operaciones.

\section{GRÁFICO 10}

Oro: Volumen producido vs volumen exportado, 1989-2013 (en miles de onzas troy)

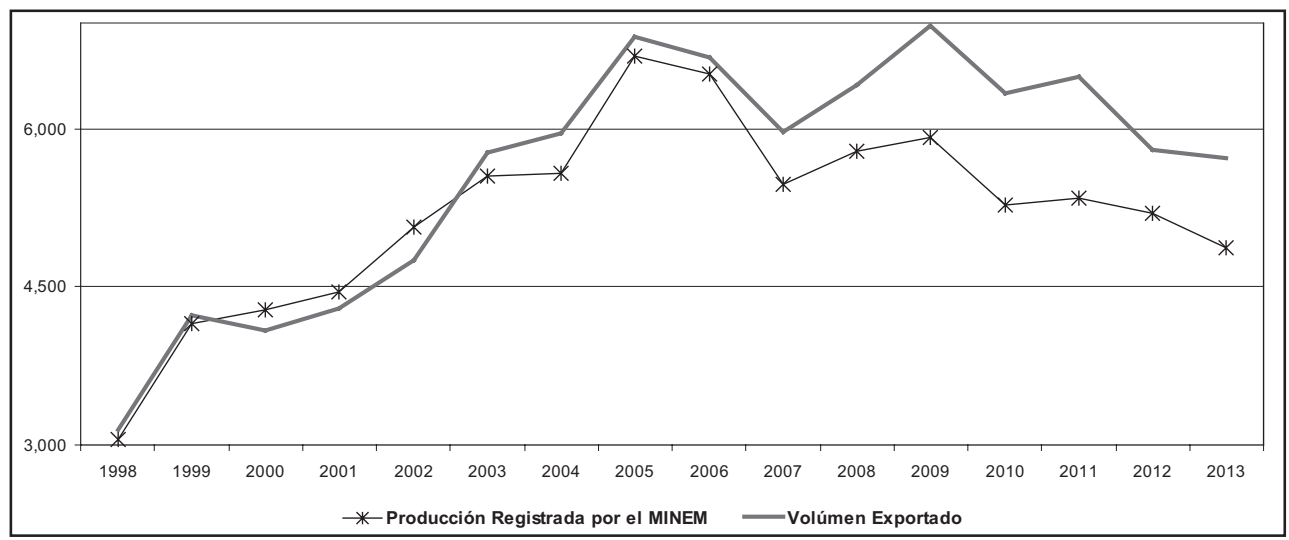

Fuente: Minem (www.Minem.gob.pe), BCRP (www.bcrp.gob.pe).

Elaboración propia.

Es decir, conforme la producción de oro se hizo más rentable, la producción ilegal $e$ informal de este metal se volvió más intensiva. En este contexto, el exceso de volumen exportado con respecto al volumen oficial de producción registrado por el Minem ${ }^{21}$ constituye una buena variable proxy para estimar la amplitud de la producción tanto de la minería ilegal como de la minería informal no estimada/registrada por dicho ministerio. Los resultados de este ejercicio nos llevan a una relectura de las estadísticas mineras del país.

21 En este trabajo, los conceptos "cifra oficial de producción de oro" o "producción oficial" comprende tanto a la producción formal como a la producción informal de Madre de Dios que es estimada y registrada por el Minem. 


\section{Víctor Torres Cuzcano}

La cifra oficial de producción de oro tendría que ser corregida hacia arriba. Durante 2003-2013, la producción total de oro en el Perú habría sido mayor en $11.0 \%$ con respecto a la cifra oficial: 2,145.9 toneladas, en lugar de las 1,934.1 toneladas que registró el Minem. Es decir, durante dicho periodo la producción ilegal/informal ascendió a 211.8 toneladas, lo que representa en promedio una producción anual de 19.3 toneladas. Este resultado superó en $18.9 \%$ las 178.1 toneladas (16.2 toneladas al año) de producción informal que estima/registra el Minem (gráfico 11).

\section{GRÁFICO 11}

Oro: Producción de la minería ilegal e informal, 2003-2013 (miles de onzas troy)

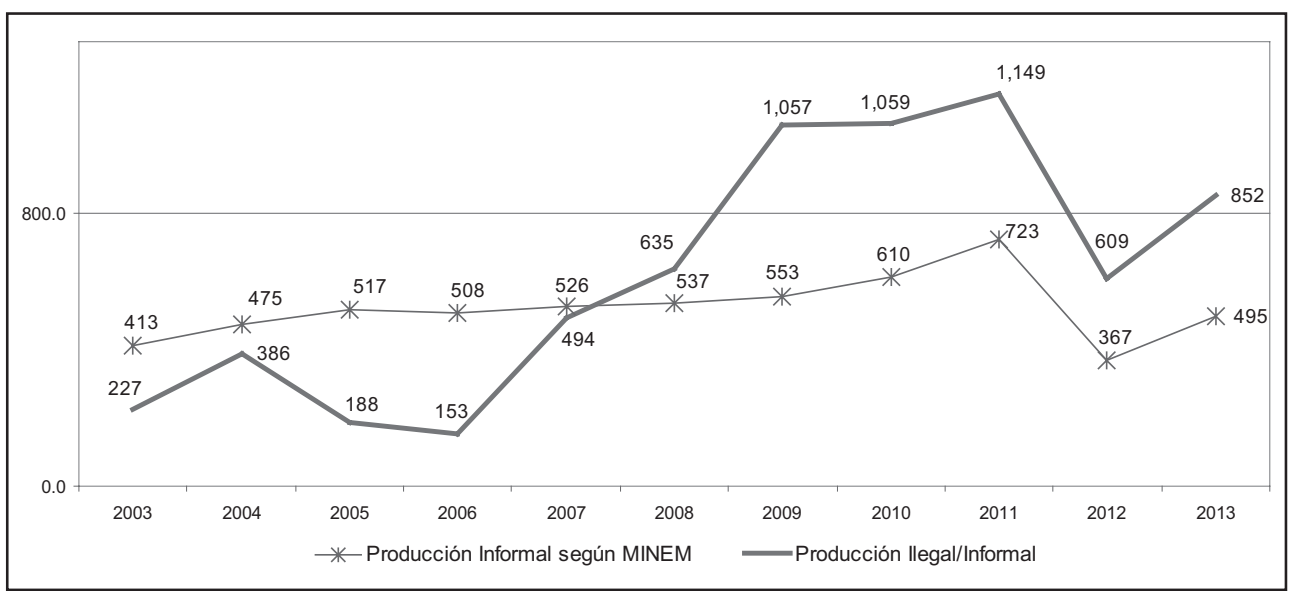

Fuente: Minem (www.minem.gob.pe), BCRP (www.bcrp.gob.pe).

Elaboración propia.

Entre 2005 y 2013, mientras que la producción oficial de oro caía en $27.2 \%$, la minería ilegal/informal incrementaba su producción en $352.3 \%$. En consecuencia, desde 2006 la menor producción de la gran minería fue compensada en parte por una producción ilegal/informal en expansión, explicando así el volumen exportado que no tiene un respaldo en la producción oficial de oro (gráfico 12). 


\section{Pensamiento Crítico Vol. 19. № 2}

GRÁFICO 12

Oro: Producción total según Minem vs producción ilegal (miles de onzas troy)

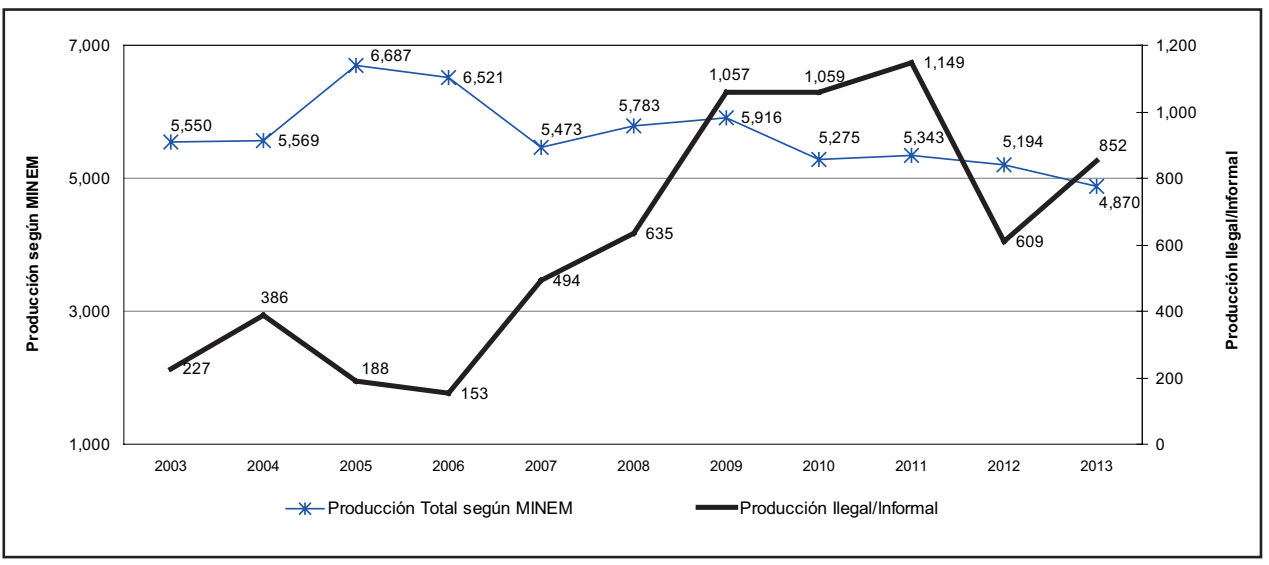

Fuente: Minem.

Elaboración propia.

Si clasificamos la producción aurífera del país en producción formal y producción ilegal/informal (incluye la producción informal estimada/registrada por el Minem), esta última representó el $22.2 \%$ de la primera durante 2003-2013. Es decir, durante este periodo el total de la producción que se obtuvo de manera informal o ilegal sumó 389.9 toneladas, lo que representa en promedio una producción anual de 35.4 toneladas.

En términos de participación relativa, la producción ilegal/informal aportó el $18.2 \%$ del total durante dicho periodo; durante 2010 y 2011 este porcentaje superó incluso el $25.0 \%$ del total (gráfico 13). 


\section{Víctor Torres Cuzcano}

GRÁFICO 13

Oro: Producción formal vs producción ilegal / informal (participación relativa)

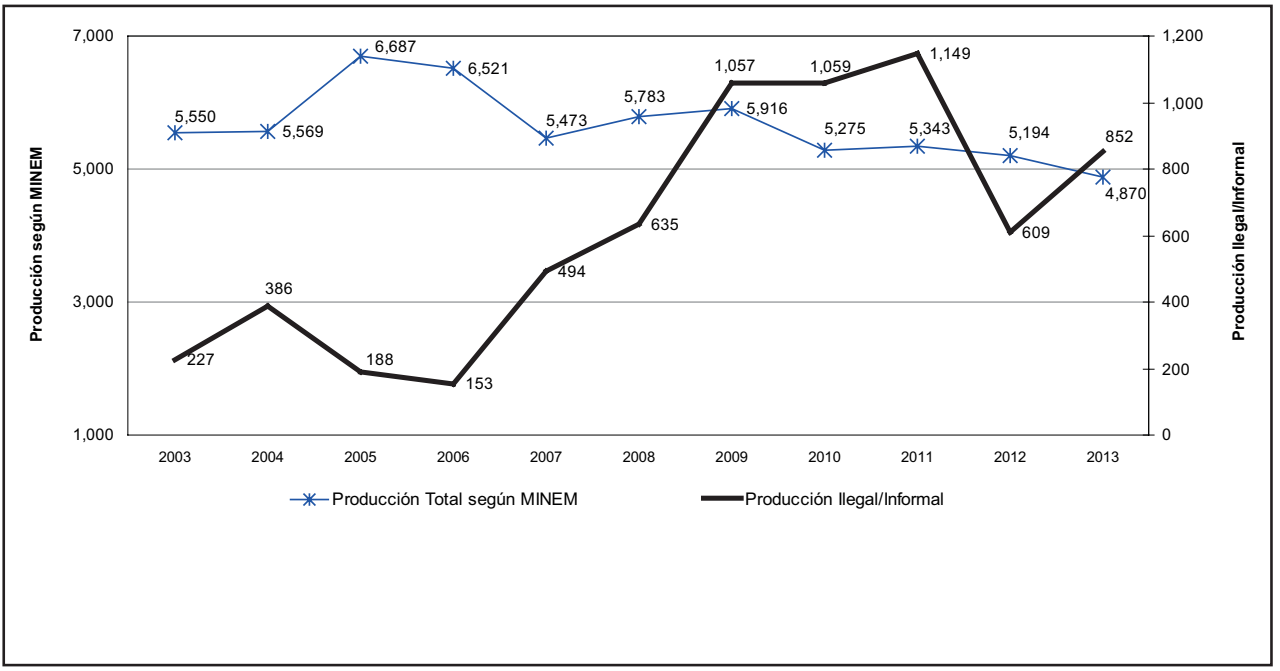

Fuente: Minem

Elaboración propia

En cuanto a las exportaciones, el 9.9\% del volumen exportado durante 2003-2013 tendría su origen tanto en la minería ilegal como en la minería informal que no estima/ registra el Minem.

Si el volumen de producción de oro no registrado por el Minem lo multiplicamos por su precio de exportación ${ }^{22}$, encontramos que US\$7,671 millones de nuestras exportaciones de oro se originaron en la producción ilegal e informal durante 20032013; es decir, el $12.0 \%$ del valor exportado durante dicho periodo.

Visto desde otro ángulo, estos US\$ 7,671 millones representan la valorización de la producción de oro que proviene tanto de la minería ilegal como de la minería informal que no estima/registra el Minem. Toda vez que la producción aluvial que el Minem atribuye al titular "Madre de Dios" también proviene de productores informales,

22 El precio de exportación del oro es el que se registra en las estadísticas del BCRP durante el referido periodo, que no tiene discrepancias significativas con la cotización internacional de este metal que registra la London Metal Exchange. 
esta debiera sumarse a la producción ilegal/informal arriba indicada para determinar el total de la producción no formal. Aplicando la misma metodología mencionada en el párrafo precedente, encontramos que la producción informal de Madre de Dios sumó US\$ 5,456 millones durante 2003-2013.

En consecuencia, el valor total de la producción ilegal/informal de oro en el Perú, registrada y no registrada, ascendió a US \$13,127 millones durante 2003-2013 (gráfico 14); monto que en promedio representó US $\$ 1,193$ millones al año.

GRÁFICO 14

Oro: Valor de la producción ilegal e informal, 2003-2013 (millones de US\$)

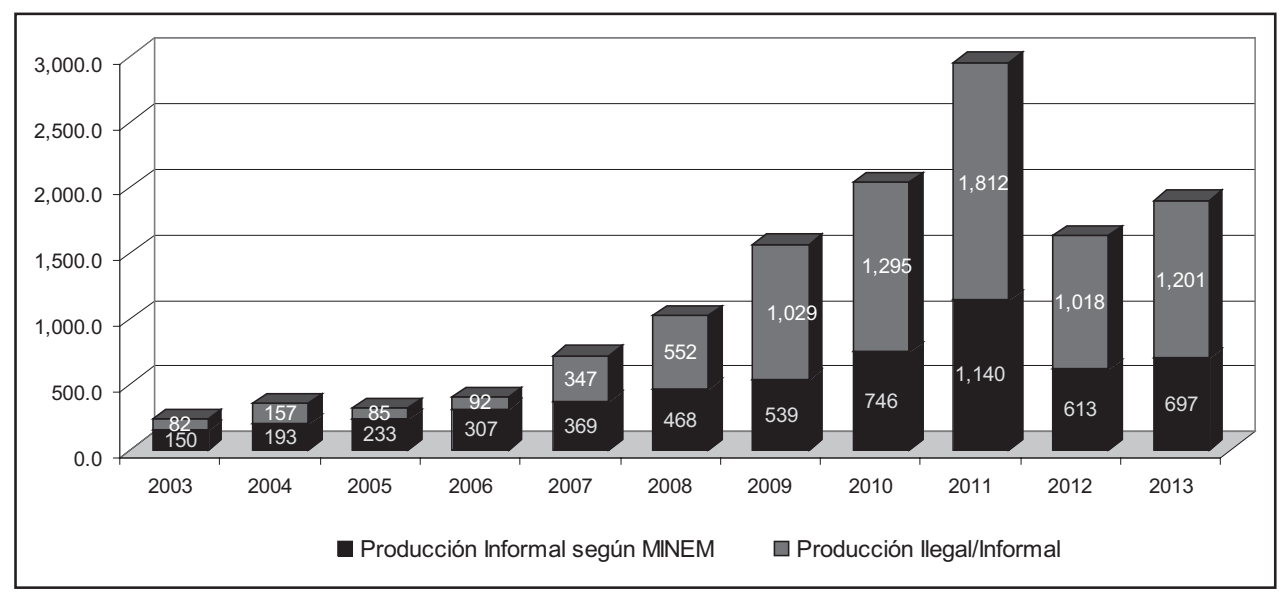

Fuente: Minem.

Elaboración propia.

\section{Efectos de la minería ilegal en los ingresos fiscales}

\subsection{Estimación de la evasión tributaria}

Los US\$13,127 millones calculados en el acápite precedente son las ventas que los productores informales/ilegales no declararon durante 2003-2013. La venta o 


\section{Víctor Torres Cuzcano}

comercialización del oro en el Perú está exonerada del pago del IGV23; en consecuencia, asumiremos que en el mercado ilegal/informal del oro no se evade el pago de este impuesto. No obstante, se trata de un supuesto bastante forzado pues -en la prácticase evade este impuesto cuando los productores ilegales/informales compran insumos también de manera informal. Asimismo, no son pocos los productores formales de Madre de Dios que han renunciado a dicha exoneración, pero en acuerdo con los acopiadores/compradores/exportadores subvalúan o atomizan sus ventas para que estas no superen el mínimo exigido por la Administración Tributaria para detraer parte del IGV correspondiente a las ventas de oro gravadas con este impuesto ${ }^{24}$.

Al margen de ello, nos concentraremos en la estimación de la evasión del Impuesto a la Renta de la Tercera Categoría; es decir, el impuesto que pagan o-deberían de pagartodas las empresas formales. Los US \$13,127 millones arriba calculados representan los ingresos totales que se obtienen en el país por la producción informal/ilegal del oro.

Para obtener la base imponible -es decir, la utilidad antes de impuesto- sobre la cual aplicar la tasa de $30 \%$ que corresponde al referido impuesto, vamos a trabajar con tres escenarios, cada uno de los cuales estará determinado por el margen de ganancia (Utilidad Antes de Impuesto/Ventas) que podría obtener un productor ilegal/informal de oro. En la práctica, estos márgenes de ganancia registran una alta dispersión, pues están influenciados por diversas variables: método de producción, tipo de mina o extracción (aluvial, subterránea, etc.), lugar o zona de producción, calidad o ley del mineral extraído, estrato minero al cual pertenece el productor, entre otras. Así, la estimación de la evasión en renta variará según el margen de ganancia que se asuma.

Según el trabajo de campo llevado a cabo por la Organización No Gubernamental CooperAcción (2009), el margen de ganancia de los productores informales aumentaría de acuerdo con el grado de mecanización del método de producción utilizado, pudiendo fluctuar entre $8.16 \%$, para un método más artesanal, como el denominado "carretilla", y $43.63 \%$, para un método semimecanizado, como el "cargador frontal".

23 En el caso de Madre de Dios, la comercialización del oro está doblemente exonerada del IGV por tratarse de una región que también se beneficia por la Ley de Zona de Selva.

24 El 01.12.10 la comercialización interna del oro y sus concentrados fue incluida en el Sistema de Detracciones del IGV, con una tasa de $12 \%$. 


\section{Pensamiento Crítico Vol. 19. No 2}

Teniendo en cuenta que la mayor parte de la producción aurífera ilegal/informal se concentra en Madre de Dios, y que en esta región los mayores volúmenes producidos se registran en zonas como Huepetuhe donde predomina el uso de métodos más mecanizados como el shute-cargador frontal, es válido suponer que la evasión tributaria más probable es aquella que se estime con un margen de ganancia que se aproxime al que obtienen los productores más mecanizados. Tal como se menciona en Torres (2007), desde al menos 1995 la mayor producción aurífera en Madre de Dios se obtiene a partir de métodos de producción semi-mecanizados. Además, como ya fue mencionado líneas arriba, desde 2005 el Minem sinceró sus registros y comenzó a clasificar la producción informal de Madre de Dios dentro del estrato de la gran y mediana minería.

En el cuadro 6 hemos estimado la evasión en renta utilizando tres márgenes de ganancia: $11.0 \%, 23.9 \%$ y $36.8 \%$. Este último, es el margen de ganancia promedio que CooperAcción (2009) obtiene para el conjunto de métodos de producción en Madre de Dios.

En dos de los escenarios más probables, con márgenes de ganancia de $23.9 \%$ y $36.8 \%$, la evasión del Impuesto a la Renta de la Tercera Categoría habría fluctuado entre US\$ 941.2 millones y US\$1,449.2 millones, respectivamente; es decir, entre US\$ 85.6 millones y US\$131.7 millones en promedio anual. La mayor parte de la evasión en renta (58.4\%) se genera tanto en la producción ilegal como en la informal no estimada/ registrada; en tanto que el $41.6 \%$ restante se genera en la producción informal que el Minem estima y registra en sus estadísticas de producción minera.

Se trata de montos de evasión nada despreciables si tenemos en cuenta que representaron entre $5.3 \%$ y $8.1 \%$ de la recaudación del Impuesto a la Renta de la Tercera Categoría del sector minero durante 2003-2013. 


\section{Víctor Torres Cuzcano}

\section{CUADRO 6}

Minería aurífera ilegal e informal: Estimación de ingresos y de evasión tributaria. Periodo acumulado, 2003-2013 (en millones de US\$)

\begin{tabular}{|c|c|c|c|}
\hline & $M G=11.0 \%$ & MG $=\mathbf{2 3 . 9} \%$ & MG $=36.8 \%$ \\
\hline \multicolumn{4}{|l|}{ INGRESOS (VENTAS TOTALES) } \\
\hline Producción Ilegal//nformal No registrada por el MINEM & $7,671.0$ & $7,671.0$ & $7,671.0$ \\
\hline Producción Informal Registrada por el MINEM & $5,456.2$ & $5,456.2$ & $5,456.2$ \\
\hline TOTAL & $13,127.2$ & $13,127.2$ & $13,127.2$ \\
\hline \multicolumn{4}{|l|}{ UTILIDAD ANTES DE IMPUESTO ${ }^{1 /}$} \\
\hline Producción Ilegal//nformal No registrada por el MINEM & 843.8 & $1,833.4$ & $2,822.9$ \\
\hline Producción Informal Registrada por el MINEM & 600.2 & $1,304.0$ & $2,007.9$ \\
\hline TOTAL & $1,444.0$ & $3,137.4$ & $4,830.8$ \\
\hline \multicolumn{4}{|l|}{ EVASIÓN EN IMPUESTO A LA RENTA 3RA. CATEGORÍA ${ }^{2 l}$} \\
\hline Producción Ilegal//nformal No registrada por el MINEM & 253.1 & 550.0 & 846.9 \\
\hline Producción Informal Registrada por el MINEM & 180.1 & 391.2 & 602.4 \\
\hline TOTAL (Millones US\$) & 433.2 & 941.2 & $1,449.2$ \\
\hline TOTAL (Millones S/.) ${ }^{3 /}$ & $1,242.3$ & $2,699.1$ & $4,155.9$ \\
\hline
\end{tabular}

1/ Para estimar las utilidades antes de impuestos, el porcentaje de Margen de Ganancia (utilidad antes de impuesto / venta) se aplica sobre los Ingresos o ventas totales.

2/ Resulta de aplicar la tasa del impuesto de $30.0 \%$ sobre la Utilidad antes de Impuesto.

3/ Se utiliza el Tipo de Cambio promedio anual publicado por el BCRP.

Fuente: Minem, BCRP.

Elaboración propia.

Los mayores montos de evasión se registraron entre 2007 y 2011, años durante los cuales la cotización del oro alcanzó sus máximos niveles y proliferaron los productores y exportadores "golondrinos" (gráfico 15). La menor evasión registrada durante 2012 puede explicarse por las acciones que durante ese año emprendió el gobierno contra la minería ilegal, así como por la presión que ejerció sobre la minería informal para que esta regularice su situación, medidas que determinaron una menor producción en este segmento. 


\section{GRÁFICO 15}

Minería aurífera informal / ilegal: Evasión del imp. renta 3ra según margen de ganancia (millones de nuevos soles)

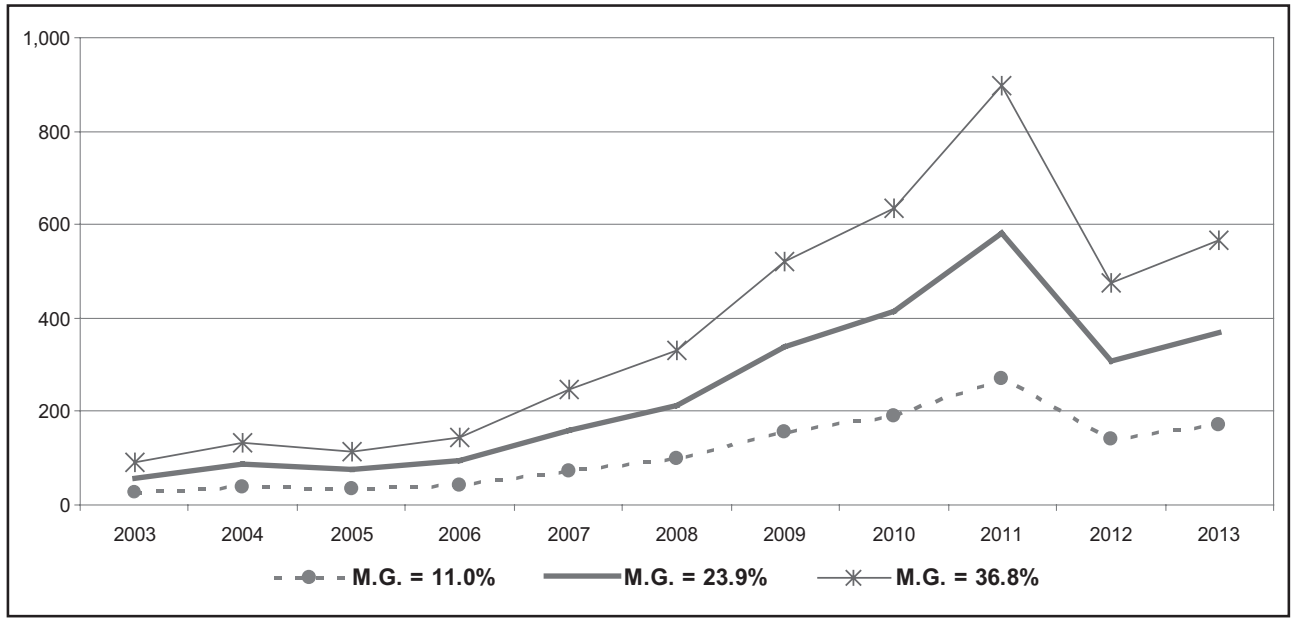

Fuente: Minem, BCRP.

Elaboración propia.

En consecuencia, la región de Madre de Dios dejó de percibir por concepto de canon minero entre US\$ 470.6 y 724.6 millones durante 2003-2013; es decir, el 50\% de los montos evadidos según los dos escenarios que más se aproximan a la realidad.

Esta estimación de la evasión en renta está, en estricto, subvaluada, pues no toma en cuenta la evasión de los mineros formales de Madre de Dios, que si bien cumplen con presentar sus declaraciones de ventas e ingresos ante la Sunat, las subvalúan para reducir el pago del Impuesto a la Renta. Asimismo, habría que sumar también la evasión por concepto del Impuesto a la Renta de los trabajadores dependientes, pues en un escenario ideal, los trabajadores mineros que laboran en la extracción aurífera informal/ ilegal deberían cumplir con el pago de este impuesto vía retenciones por parte de sus empleadores. Insisto, este ya es un escenario demasiado ideal dados los bajos niveles de institucionalidad que existen en el país. 


\section{Víctor Torres Cuzcano}

\subsection{Los efectos en la recaudación}

La evasión tributaria en la minería ilegal e informal no es la principal vía a través de la cual la actividad minera ha afectado la recaudación de los ingresos fiscales durante los últimos años. Lo ha sido sobre todo la caída de sus exportaciones.

En el caso del oro, el valor exportado se contrajo en $-5.2 \%$ y $-16.9 \%$ durante 2012 y 2013, respectivamente, debido a que el descenso en su cotización desde septiembre de 2011 se conjugó con una caída sostenida en la producción de este metal. Durante enero-agosto 2014, comparado con similar periodo de 2013, el valor exportado cayó en $39.6 \%$.

Estos resultados recientes han tenido una influencia determinante en los menores ingresos fiscales debido a que durante el boom minero la recaudación tributaria reposó de manera significativa en los recursos derivados de las exportaciones del sector. La participación relativa de la minería en la recaudación total de tributos internos aumentó de $2.9 \%$ en 1995 a $24.7 \%$ en 2007 . En el caso del Impuesto a la Renta de la Tercera Categoría, la minería -que solo aportaba un 6.8\% de la recaudación en 1995- subió su participación a 50.9\% durante 2007. Hacia fines de 2013, estas participaciones relativas habían bajado a $9.4 \%$ y $14.7 \%$, respectivamente.

La recaudación minera (tributos internos), después de incrementarse a una tasa promedio de $47.0 \%$ en términos reales durante 2010-2011, cayó abruptamente en $8.9 \%$ durante 2012 y en $34.3 \%$ durante 2013. Durante enero-julio de 2014, se contrajo en $21.3 \%$ con respecto a similar periodo de 2013. Consecuentemente, la recaudación nacional (tributos internos), que durante 2010-2011 creció a una tasa promedio de $16.1 \%$, bajó su ritmo de crecimiento a $2.9 \%$ durante 2013 , y durante enero-julio de 2014 lo hizo a $1.3 \%$.

Para el periodo 1995-2013, un simple ejercicio de correlación entre las variables exportación de oro - cotización del oro arroja un coeficiente de determinación R2 de $96.6 \%$, en tanto que el par de variables exportación de oro-producción de oro registra un $\mathrm{R} 2$ de $28.4 .0 \%$ (gráfico 16). 


\section{Pensamiento Crítico Vol. 19. № 2}

\section{GRÁFICO 16}

Oro: Exportación, producción y cotización, 1995-2013 (año base 1995 = 100)

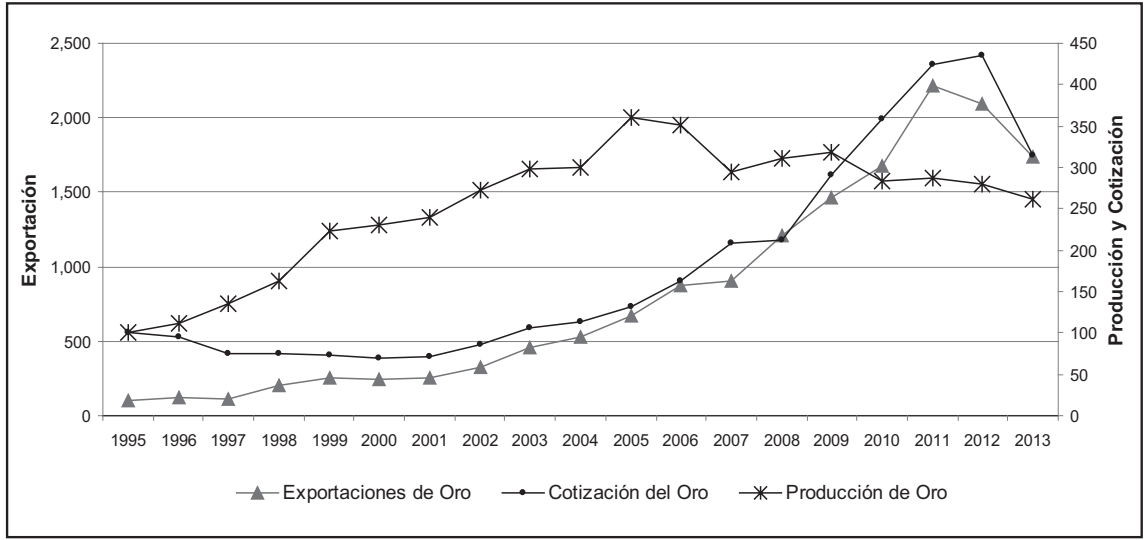

Fuente: BCRP, Minem.

Elaboración propia.

Para este mismo periodo, el par de variables recaudación minera-cotización del oro arroja un coeficiente de determinación R2 de $74.3 \%$, en tanto que el par de variables recaudación minera-producción de oro registra un $\mathrm{R} 2$ de $30.0 \%$ (gráficos 17 y 18).

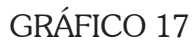

Recaudación minera y cotización del oro, 1995-2013 (año base 1995 = 100)

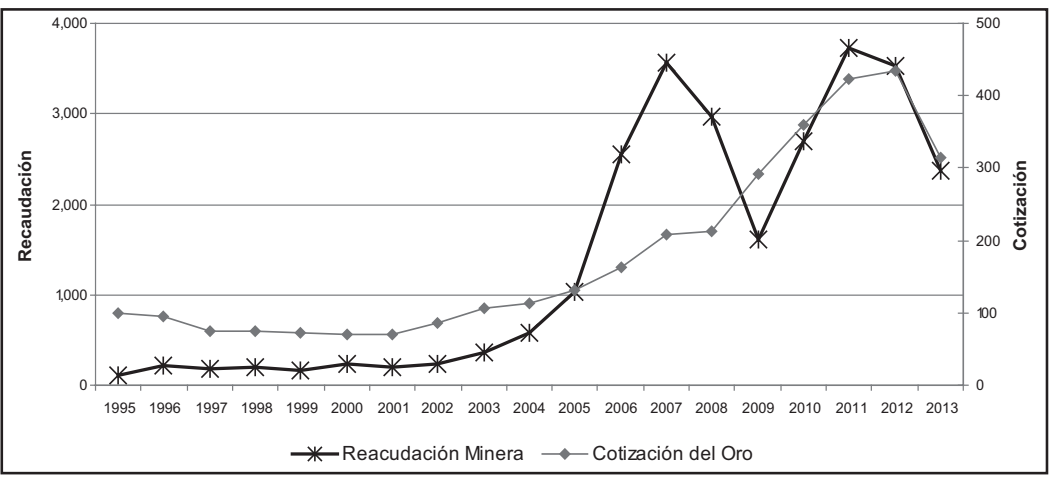

Fuente: BCRP, SUNAT.

Elaboración propia. 


\section{GRÁFICO 18}

Recaudación minera y producción del oro, 1995-2013 (año base 1995 = 100)

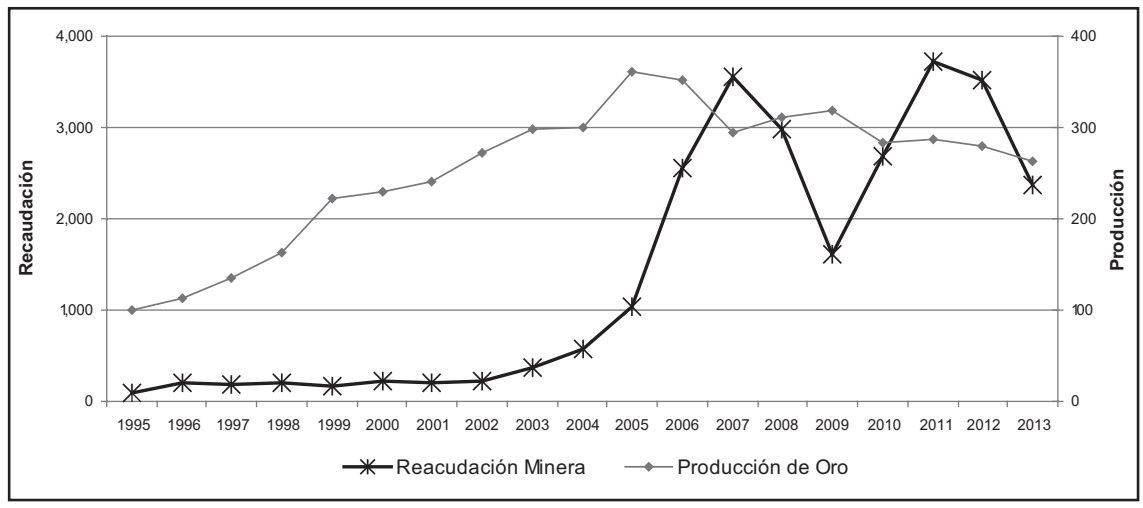

Fuente: Minem, SUNAT.

Elaboración propia.

En consecuencia, la recaudación nacional perdió dinamismo influenciada por la menor recaudación minera; a su vez, esta se desplomó porque las exportaciones mineras se vinieron abajo cuando se acentuó la tendencia a la baja del precio de los metales. En el caso del oro, la menor producción contribuyó a acentuar esta tendencia reciente, pero no fue su causa principal inmediata, pues la producción ya venía cayendo desde 2006.

\subsection{Algunas mediciones econométricas ${ }^{25}$}

Tomando como referencia el análisis precedente, vamos a analizar el grado de relación econométrica entre algunas variables. Para tal efecto, utilizaremos el modelo de cointegración que consiste en ver el grado de relación de las variables en el tiempo (largo plazo).

Se realizaron los análisis correspondientes, como transformar las variables a su forma logarítmica con la finalidad de suavizar las series, comprobando que cada serie sea integrada de orden (1), es decir que estas no sean estacionarias. Para tal efecto, se aplicó el test de Dickey Fuller aumentado; asimismo, los test de normalidad, autocorrelación y

25 Para este análisis econométrico se contó con el apoyo del Asistente de Investigación Marco Antonio Mendoza Obregón. 


\section{Pensamiento Crítico Vol. 19. $N^{\circ} 2$}

heterocedasticidad, los cuales se cumplieron de manera adecuada. Se aplicó también el test de cointegración de Johansen, en sus dos compenentes: el test de la traza y el test del máximo valor propio, los cuales nos permiten saber cuántos vectores de cointegración posee el modelo. Los modelos se trabajaron con un nivel de significancia de $95 \%$.

\section{Caso 1:}

Recaudación minera $=f$ (cotización oro, conflictos socioambientales, PBI minero, producción oro)

Hipótesis nula $=$ existe un vector de cointegración.

Periodo de análisis: enero 2005 - agosto 2014 (mensual).

Resultados del test de cointegración: test de la traza y test de máximo valor propio:

\begin{tabular}{|ccccc|}
\hline \multicolumn{5}{c|}{ Unrestricted Cointegration Rank Test (Trace) } \\
\hline $\begin{array}{c}\text { Hypothesized } \\
\mathrm{N}^{\circ} \text { of CE }(\mathrm{s})\end{array}$ & Eigenvalue & $\begin{array}{c}\text { Trace } \\
\text { Statistic }\end{array}$ & $\begin{array}{c}0.05 \\
\text { Critical Value }\end{array}$ & Prob.** \\
\hline None $^{*}$ & 0.325777 & 90.27620 & 69.81889 & 0.0005 \\
At most 1 & 0.183418 & 45.73217 & 47.85613 & 0.0781 \\
At most 2 & 0.099571 & 22.83521 & 29.79707 & 0.2543 \\
\hline \multicolumn{5}{c}{ Unrestricted Cointegration Rank Test (Maximum Eigenvalue) } \\
\hline Hypothesized & Eigenvalue & Max-Eigen & 0.05 & \multirow{2}{*}{ Prob.** } \\
$\mathrm{N}^{\circ}$ of CE(s) & 0.325777 & 44.54403 & 33.87687 & 0.0019 \\
\hline None ${ }^{*}$ & 0.183418 & 22.89695 & 27.58434 & 0.1779 \\
At most 1 & 0.099571 & 11.85187 & 21.13162 & 0.5624 \\
At most 2 & & & \\
\hline
\end{tabular}

Sobre la base de estos resultados se acepta la hipótesis nula, la cual nos dice que el modelo presenta un vector de cointegración; esto debido a que la probabilidad es mayor que 0.05. Este resultado se repite tanto para el test de la traza como para el del máximo valor propio; por tanto, algunas de las variables independientes del modelo llegarán a presentar cointegración con la variable dependiente.

\section{리르}


Ecuación de cointegración:

\begin{tabular}{|ccccc|}
\hline $\begin{array}{c}\text { 1 Cointegrating } \\
\text { Equation(s): }\end{array}$ & Log likelihood & \multicolumn{2}{c|}{652.368} & \\
\hline \multicolumn{5}{|c|}{ Normalized cointegrating coefficients (standard error in parentheses) } \\
\hline LRECA_TOTAL_MIN & LCOTIZA_AU_PROM & LCONFLICTOS & LPBI_MINERIA & LPROD_AU \\
\hline 1 & -1.140508 & 0.19631 & 3.199926 & 0.498775 \\
& $(0.347891)$ & $(0.189044)$ & $(1.315626)$ & $(0.589511)$ \\
\hline
\end{tabular}

Este cuadro se lee de la siguiente manera:

\section{LRECA_TOTAL_MIN $=1.140 *$ LCOTIZA_AU_PROM $-0.196 *$ LCONFLICTOS - 3.199*LPBI_MINERIA - 0.498*LPROD_AU}

El análisis de los signos:

$(+$ ): Presenta una relación de cointegración.

( - ): No presenta una relación de cointegración.

Se observa que la cotización del oro es la única variable que cointegra con la recaudación minera, lo cual indicaría que la evolución de esta última ha estado determinada principalmente por el precio internacional del oro. Las otras tres variables consideradas en este modelo (producción de oro, conflictos socioambientales y PBI minero) no explican el comportamiento de la variable dependiente: recaudación minera.

\section{Caso 2:}

Recaudación total de tributos internos $=\mathrm{f}$ (producción oro, cotización oro, $\mathrm{PBI}$ minero, conflictos socioambientales).

Hipótesis nula $=$ existe un vector de cointegración. 


\section{Pensamiento Crítico Vol. 19. № 2}

Periodo de análisis: enero 2005 - agosto 2014 (mensual).

Resultados del test de cointegración: test de la traza y test de máximo valor propio:

\begin{tabular}{|c|c|c|c|c|}
\hline \multicolumn{5}{|c|}{ Unrestricted Cointegration Rank Test (Trace) } \\
\hline $\begin{array}{c}\text { Hypothesized } \\
\mathrm{N}^{\circ} \text {. of } \mathrm{CE}(\mathrm{s})\end{array}$ & Eigenvalue & $\begin{array}{l}\text { Trace } \\
\text { Statistic }\end{array}$ & $\begin{array}{c}0.05 \\
\text { Critical Value }\end{array}$ & Prob.** \\
\hline None * & 0.393488 & 99.62768 & 69.81889 & 0.0000 \\
\hline At most 1 & 0.172762 & 43.12429 & 47.85613 & 0.1296 \\
\hline At most 2 & 0.092618 & 21.69243 & 29.79707 & 0.3159 \\
\hline \multicolumn{5}{|c|}{ Unrestricted Cointegration Rank Test (Maximum Eigenvalue) } \\
\hline $\begin{array}{l}\text { Hypothesized } \\
\mathrm{N}^{\circ} \text {. of } \mathrm{CE}(\mathrm{s})\end{array}$ & Eigenvalue & $\begin{array}{c}\text { Max-Eigen } \\
\text { Statistic }\end{array}$ & $\begin{array}{c}0.05 \\
\text { Critical Value }\end{array}$ & Prob.** \\
\hline None* & 0.393488 & 56.50339 & 33.87687 & 0.0000 \\
\hline At most 1 & 0.172762 & 21.43186 & 27.58434 & 0.2510 \\
\hline At most 2 & 0.092618 & 10.98261 & 21.13162 & 0.6491 \\
\hline
\end{tabular}

Se acepta la hipótesis nula, la cual nos dice que el modelo presenta un vector de cointegración; esto debido a que la probabilidad es mayor que 0.05. Este resultado se repite tanto para el test de la traza como para el del máximo valor propio.

Ecuacion de cointegración:

\begin{tabular}{|c|c|c|c|c|}
\hline \multicolumn{2}{|c|}{1 Cointegrating Equation(s): } & Log likelihood & 760.5751 & \\
\hline \multicolumn{5}{|c|}{ Normalized cointegrating coefficients (standard error in parentheses) } \\
\hline LRECA_TOT_PERU & LPROD_AU & $\begin{array}{l}\text { LCOTIZA_AU_ } \\
\text { PROM }\end{array}$ & LPBI_MINERIA & LCONFLICTOS \\
\hline \multirow[t]{2}{*}{1.000000} & 0.838646 & -0.549244 & -0.152516 & 0.039509 \\
\hline & $(0.16369)$ & $(0.09670)$ & $(0.36933)$ & $(0.05266)$ \\
\hline
\end{tabular}

El cuadro anterior se lee de la siguiente manera:

LRECA_TOT_PERU $=-0.838646 *$ LPROD_AU $+0.549244 *$ LCOTIZA_AU_ PROM + 0.152516*LPBI_MINERIA - 0.039509*LCONFLICTOS 


\section{Víctor Torres Cuzcano}

Según los resultados precedentes, la recaudación de tributos internos está influenciada tanto por el PBI minero como por la cotización del oro, pero esta última variable es la que ejerce el principal efecto. Para el periodo analizado, la producción de oro y los conflictos socioambientales no influyeron en la recaudación total.

\section{Conclusiones}

Durante el presente siglo, cerca del $87 \%$ de la producción de oro se concentró en la gran y mediana minería. En el otro extremo, la minería aluvial (léase informal) bajó su participación relativa de $12.4 \%$ a $5.5 \%$ entre 2000 y $2014^{26}$, después de haber aportado más de la mitad de la producción aurífera nacional hasta 1994. Sin embargo, la participación relativa de este estrato está subvaluada para los últimos años, pues no toma en cuenta aquella producción ilegal e informal que no es estimada ni registrada por el Minem, la que se fue expandiendo conforme aumentaba la cotización internacional del oro y se debilitaba la participación de las principales empresas auríferas que operan en el país.

El boom minero nacional que comenzó hacia fines de 2002, se sustentó fundamentalmente en un efecto-precio; es decir, en el paulatino y sostenido incremento de la cotización internacional de los metales que producimos y exportamos. En el caso de la minería aurífera, hasta 2005 este efecto-precio se reforzó con un efectoproducción positivo, resultado de las inversiones efectuadas durante la última década del siglo pasado. Esta virtuosa combinación dio como resultado la obtención de elevadas ganancias extraordinarias en el sector.

Desde 2006, la producción aurífera inició una tendencia descendente que ha continuado hasta el presente. En un primer momento, ello se debió a problemas propios a la dinámica productiva de la gran minería; posteriormente, dicha tendencia se acentuó con el surgimiento de conflictos socioambientales y el descenso en la cotización internacional del oro. Por tanto, desde 2006 el boom de las exportaciones de oro se sustentó exclusivamente en un efecto-precio.

La tendencia a la baja del precio del oro desde septiembre de 2011 hasta el presente ha condicionado una menor inversión en esta actividad, lo que ha reforzado el

26 Cifra estimada para 2014. 


\section{Pensamiento Crítico Vol. 19. № 2}

descenso de la producción. Se trata de una sobrerreacción de la gran minería, pues si bien esta ya no está obteniendo las ganancias extraordinarias de los años precedentes, sigue acumulando beneficios debido a que el precio del oro se mantiene por encima de sus niveles de largo plazo.

Después de alcanzar un pico en 1992, la concentración de la producción en el mercado aurífero nacional inició un camino descendente, hasta registrar un bajo nivel de concentración en la actualidad. Este resultado estuvo determinado por dos factores principales: una cuasi atomización de los productores de oro y -principalmentela menor producción de las principales empresas de la gran minería. Esta particular combinación de menor producción con una mayor cantidad de productores, se explica por la presencia de "productores golondrinos"; es decir, productores que declaran su producción solo durante muy pocos meses del año y luego desaparecen del escenario.

En el mercado de las exportaciones auríferas, los niveles de concentración han seguido una tendencia similar a la observada en la producción, también con la presencia de "exportadores golondrinos" y una drástica caída de los valores de exportación de las principales empresas.

Es bastante probable que estos productores y exportadores "golondrinos" estén declarando formalmente solo una parte de su producción y/o exportación; la diferencia la canalizan de manera ilegal o informal. De otro lado, el singular descenso en los niveles de concentración agrega mayor incertidumbre en el mercado aurífero nacional; lo vuelve menos predecible. Su evolución ya no reposa en la producción o exportación regular de unas pocas empresas (grandes y medianas), sino que se ve influenciada por empresas que operan a medio camino entre la formalidad y la ilegalidad. Durante 2013, un exportador "golondrino" fue el cuarto exportador aurífero más importante del país.

Si bien los documentos oficiales utilizan el concepto de minería ilegal desde al menos 2010, recién desde abril de 2012 se lo define de manera explícita y se lo diferencia de la minería informal. Ambas actividades se practican actualmente en 21 de las 25 regiones del país; sin embargo, la región de Madre de Dios es un caso aparte, no solo por concentrar la mayor parte de la producción y del número de productores, sino también por sus efectos nefastos en el ecosistema y en la vida de las personas involucradas. 


\section{Víctor Torres Cuzcano}

¿Qué factores han determinado que la minería aurífera ilegal o informal se convierta en una suerte de pandemia en el Perú? Tres principalmente: el alza sostenida del precio internacional del oro que ha justificado con creces el riesgo de operar en la ilegalidad e informalidad, las restricciones estructurales de nuestra economía para generar adecuados puestos de trabajo, y una preocupante debilidad institucional. No se trata de la debilidad institucional de un gobierno en particular, sino la del Estado mismo. Desde inicios del siglo XXI, hasta el presente, los esfuerzos oficiales llevados a cabo para formalizar a los mineros informales -que tampoco han sido muchos- han fracasado.

Desde 2003, el volumen exportado de oro se fue divorciando del volumen de producción que registra el Minem, abriendo la interrogante sobre el origen del oro exportado "en exceso". Dicho exceso puede atribuirse tanto a la producción aurífera ilegal como a la producción informal no registrada por el Minem. La aceptación de esta hipótesis nos conduce a una relectura de las estadísticas mineras del país. Así, durante 2003-2013, la producción total de oro en el Perú habría sido mayor en $11.0 \%$ con respecto a la cifra oficial. En este periodo, la producción ilegal/informal habría ascendido a 211.8 toneladas, lo que representa en promedio una producción anual de 19.3 toneladas de oro. Asimismo, cerca del $10 \%$ del volumen de oro que se exportó durante 2003-2013 tendría su origen tanto en la minería ilegal como en la minería informal que no estima/registra el Minem.

Toda vez que entre 2005 y 2013, la producción aurífera oficial se contrajo, en tanto que la producción ilegal/informal se multiplicó en más de cuatro veces, podemos concluir que desde 2006 la menor producción de la gran minería fue compensada en parte por una producción ilegal/informal que es la que explica esa parte del volumen exportado que no encuentra justificación en la producción oficial del oro.

En términos de valor, la producción ilegal/informal ascendió a US\$ 7,671 millones durante 2003-2013. Toda vez que la producción informal de Madre de Dios -estimada/ registrada por el Minem- ascendió a US\$ 5,456 millones durante dicho periodo, el valor total de la producción ilegal/informal de oro en el Perú ascendió a US\$13,127 millones; monto que en promedio representó US\$1,193 millones al año.

Tomando como referencia esta valorización de la producción ilegal/informal de oro, estimamos que la evasión tributaria en el Impuesto a la Renta de la Tercera 


\section{Pensamiento Crítico Vol. 19. No 2}

Categoría fluctúa entre US\$ 86 millones y US\$ 132 millones en promedio anual en los dos escenarios más probables de los tres considerados en este trabajo. Poco más del $58 \%$ de esta evasión se genera en la producción ilegal/informal que no es estimada/ registrada por el Minem. Los mayores montos de evasión se registraron entre 2007 y 2011, años durante los cuales la cotización del oro alcanzó sus máximos niveles y proliferaron los productores y exportadores "golondrinos".

En consecuencia, la región de Madre de Dios dejó de percibir por concepto de canon minero entre US\$ 43 y US\$ 66 millones en promedio anual durante el periodo 2003-2013.

Además de la evasión tributaria por parte de la minería ilegal/informal, durante los últimos años la minería metálica también ha afectado la recaudación fiscal debido a la caída de las exportaciones del sector. La recaudación nacional perdió dinamismo desde 2013 debido a que cayó la recaudación minera; a su vez, esta se desplomó porque las exportaciones mineras se vinieron abajo cuando se acentuó la tendencia a la baja del precio de los metales. En el caso del oro, la menor producción contribuyó a acentuar esta tendencia reciente, pero no fue su causa principal, pues la producción ya venía cayendo desde 2006.

Finalmente, la minería ilegal e informal se expandió durante la última década porque se convirtió en un negocio muy rentable debido al constante incremento en la cotización internacional del oro. En consecuencia, la actual tendencia a la baja en la cotización de este metal, de continuar, abre un escenario más propicio para erradicar la minería ilegal y formalizar a aquellos que deseen continuar en esta actividad, pero sin atentar contra los servicios ambientales y la salud de las personas involucrados.

\section{Referencias bibliográficas}

BCRP (1996-2013). Memoria. Lima: Banco Central de Reserva del Perú.

COOPERACCIÓN (2009). Estudio diagnóstico de la actividad minera artesanal en Madre de Dios. Lima: CooperAcción-Caritas Madre de Dios-Conservación Internacional.

Minem (1999-2013). Anuario Minero. Lima: Ministerio de Energía y Minas. 


\section{Víctor Torres Cuzcano}

TORRES CUZCANO, Víctor (2013). Grupos económicos y bonanza minera en el Perú. El caso de cinco grupos mineros nacionales. Lima: CooperAcción.

TORRES CUZCANO, Víctor (2007). Minería artesanal y minería a gran escala en el Perú: El caso del oro. Lima: CooperAcción. 